\title{
Synthesis and Biological Evaluation of Novel L-Homoserine Lactone Analogs as Quorum Sensing Inhibitors of Pseudomonas aeruginosa
}

\author{
Haoyue Liu, ${ }^{a, b, c}$ Qianhong Gong, ${ }^{d}$ Chunying Luo, ${ }^{a, b, c}$ Yongxi Liang, ${ }^{a, b, c}$ Xiaoyan Kong,,${ }^{a, b, c}$ \\ Chunli Wu, ${ }^{*, a, b, c}$ Pengxia Feng, ${ }^{a, b, c}$ Qing Wang, ${ }^{a, b, c}$ Hui Zhang, ${ }^{a, b, c}$ and M.A. Wireko ${ }^{a, b, c}$ \\ ${ }^{a}$ School of Pharmaceutical Sciences, Zhengzhou University; Zhengzhou 450001, P. R. China: ${ }^{b}$ Key Laboratory of \\ Technology of Drug Preparation (Zhengzhou University), Ministry of Education of China; Zhengzhou 450001, P. R. \\ China: ${ }^{c}$ Key Laboratory of Henan Province for Drug Quality and Evaluation; Zhengzhou 450001, P. R. China: and \\ ${ }^{d}$ Key Laboratory of Marine Drugs, Chinese Ministry of Education, School of Medicine and Pharmacy, Ocean \\ University of China; Qingdao 266003, P. R. China. \\ Received May 3, 2019; accepted July 3, 2019
}

\begin{abstract}
In this study, we synthesized four series of novel L-homoserine lactone analogs and evaluated their in vitro quorum sensing (QS) inhibitory activity against two biomonitor strains, Chromobacterium violaceum CV026 and Pseudomonas aeruginosa PAO1. Studies of the structure-activity relationships of the set of $\mathrm{L}-$ homoserine lactone analogs indicated that phenylurea-containing $N$-dithiocarbamated homoserine lactones are more potent than $(Z)-4$-bromo-5-(bromomethylene)-2(5H)-furanone $(\mathrm{C30})$, a positive control for biofilm formation. In particular, compared with $\mathrm{C30}$, QS inhibitor 11f significantly reduced the production of virulence factors (pyocyanin, elastase and rhamnolipid), swarming motility, the formation of biofilm and the mRNA level of QS-related genes regulated by the QS system of PAO1. These results reveal 11f as a potential lead compound for developing novel antibacterial quorum sensing inhibitors.
\end{abstract}

Key words quorum sensing; L-homoserine lactone; Pseudomonas aeruginosa; dithiocarbamate; phenylurea; benzothiazolyl

\section{Introduction}

$N$-Acyl homoserine lactones (AHLs) are well-known quorum sensing molecules of Gram-negative bacteria.,2) For example, Pseudomonas aeruginosa regulates its physiological activity by releasing $N$-(3-oxododecanoyl)-L-homoserine lactone $^{3,4)}$ (OdDHL, Fig. 1). Previous studies have shown that AHLs regulate the production of biofilm and virulence factors that include elastase and pyocyanin. ${ }^{5-7)}$ Thus, many bacteria tend to express virulence factors when the concentration of AHLs they have generated is high enough to overcome inherent host defenses. ${ }^{8,9)}$

Expression of virulence genes is also connected with las, rhl and Pseudomonas quinolone signal (PQS) systems which are important quorum sensing (QS) systems. ${ }^{10-13)}$ LasI, for example, directs the synthesis of OdDHL in the las QS system. Once OdDHL reaches a critical threshold concentration, it binds to transcriptional regulatory protein las $R .^{14)}$ The QS network of $P$. aeruginosa is very complicated, with each signaling mechanism related to and affecting another. The las system is thought to be at the top of the regulatory network, which can positively regulate expression of the rhlI/R gene, the $p q s A B C D E$ gene cluster and the $p q s R$ gene. ${ }^{3)}$

Bacteria gain resistance to antibiotics due to the ease with which their biofilm and virulence factors induce mutations that allow them to evade the toxic effects of antibiotics. $\left.{ }^{15,16}\right)$ Quorum sensing inhibitors (QSIs) are thus considered a new direction for antibacterial drug discovery because they only inhibit the virulence factors of bacteria and do not interfere with the normal physiological activities of pathogens, so a resistance response is not triggered. ${ }^{17-19)}$

Aromatic thioethers are a class of important sulfur-containing derivatives with biological activities, and have attracted the interest of scientific researchers. For example, cefazolin exhibits a potent inhibitory effect against Pneumococcus and Haemophilus influenza. ${ }^{20)}$ Moreover, the aromatic thioether group has long been used as a linker to connect different biologically active moieties in the design of novel compounds. ${ }^{21-23)}$ The phenylurea moiety has biological activities, including antibacterial, anticancer and insecticide ${ }^{24)}$ activities, and phenylurea derivatives have been found to be fungicidal against Rhizoctonia solani and Pellicularia spp. ${ }^{25)}$

Brominated furanones (BFs) are a leading class of anti-virulence compounds and have been proven to prevent the normal operation of the QS system, which competes with AHLs for a receptor protein. ${ }^{26)}$ We chose the frequently used $(Z)$-4-bromo5-(bromo-methylene)-2(5H)-furanone (C30, Fig. 1) as a positive control for inhibition of the las system for our evaluation of the anti-biofilm formation activity of our analogs. ${ }^{27)}$

Inspired by previous research about the antibacterial evaluation of AHL analogs containing thioester linkages, ${ }^{28)}$ we herein report the design and synthesis of novel L-homoserine lactone analogs by introducing a thioether group (Fig. 1 7a-d, $\mathbf{8 a}-\mathbf{c}$ ) or a phenylurea group (Fig. 1 11a-i, 12a-c) at the side chain terminus, and the antibacterial activities of these analogs against the $P$. aeruginosa QS system. Structure-activity relationships (SARs) and molecular docking studies were conducted to rationalize the mechanism of the action of these QSIs.

\section{Results and Discussion}

Chemistry The L-homoserine lactone hydrochloride $\mathbf{4}$ was efficiently synthesized from methionine (1) following previously reported methods ${ }^{29)}$ (Chart 1). The reported optical rotation of compound $4\left([\alpha]_{\mathrm{D}}^{20}=-27.5^{\circ}(c 0.2\right.$, water $\left.)\right)$ was used 
to confirm its stereochemistry. ${ }^{30)}$ With crucial intermediate 4 in hand, four series of novel L-homoserine lactone (HL) analogs were synthesized by introducing different moieties onto the amine.

Acyl compounds 5 and $\mathbf{6}$ were formed by reacting 4 with chloroacetyl chloride and 3-chloropropionyl chloride, respectively, under Schotten-Baumann conditions at room temperature $^{31,32)}$ Compound series I and II were prepared by reacting different mercapto compounds with $\mathbf{5}$ and $\mathbf{6}$, respectively, in the presence of $\mathrm{K}_{2} \mathrm{CO}_{3}{ }^{33)}$ (Chart 2). After the reaction of compound 4 with $\mathrm{CS}_{2}$, compound series III were synthesized by one-pot reaction with compounds $\mathbf{1 0 a}-\mathbf{i}^{34)}$ (Chart 3). Compound series IV were synthesized by coupling compounds 10a-c with compound $4^{35)}$ (Chart 3). The structures and yields of these four synthetic series are shown in Table 1 and Table 2.

Biological Evaluation A QSI screening model (las system model: QSIS-lasI ${ }^{36)}$ ) was used to evaluate the inhibitory activity of newly synthesized compounds against $P$. aeruginosa. This screening model is based on the sucrose lethal gene $\operatorname{sac} B$ being activated after self-expressed or externally added signal molecules bind to the LasR protein expressed by the P. aeruginosa las system. The growth of bacteria can be inhibited in LB medium containing sucrose. Thus, if QSIs are added into LB medium, the expression of the $s a c B$ gene will be inhibited, meaning the bacteria can grow normally. This screening principle is consistent with the series of high throughput QSI screening models constructed by Rasmussen's laboratory. ${ }^{37)}$ The inhibitory effects of all compounds of the four series against the P. aeruginosa PAO1 las system are shown in Fig. 2.

It can be seen from Fig. 2 that analogs $7 \mathbf{b}, 8 \mathbf{b}, 7 \mathbf{c}$ and $8 \mathbf{c}$ containing acyl homoserine lactones with benzothiazolyl or 4-chlorophenyl substituents showed significant inhibitory<smiles>CCCCCCCCCC(=O)CC(=O)N[C@H]1CCOC1=O</smiles>

OdDHL
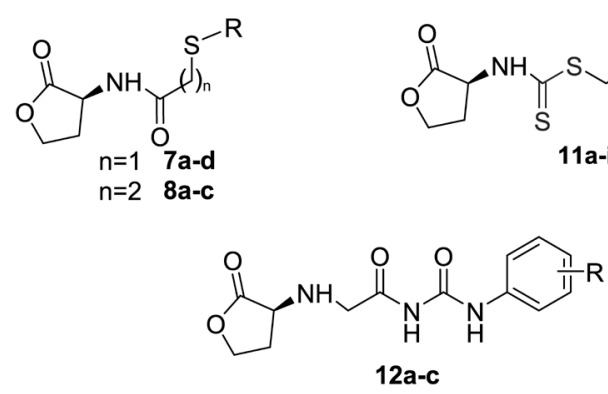

Fig. 1. Structures of OdDHL, C30 and the Active Core Group of the Three Series of Target Compounds activity of the las QS system, and were more potent than the positive control (C30). However, analogs 7a, 7d and $\mathbf{8 a}$ had no effect on QS. 7b, 8b and 8c showed excellent inhibitory activity against CV026 in Figure S1. According to the biological data for series I and II against CV026, it can be seen that the extra carbon atom of $\mathbf{8 c}$ increased its inhibitory activity compared with that of its analog $7 \mathbf{c}$.

Surprisingly, almost all compounds of series III, containing both phenylurea groups and dithiocarbamate groups, exhibited remarkable QS inhibitory (QSI) activity against CV026 (Fig. S1) and PAO1 (Fig. 2). However, only the analogs with the electron-donating groups on the terminal phenyl group (11b-f, 11h and 11i) showed powerful inhibitory activity against the las system. These results indicated that the position and electronic character of the substituents on the terminal phenyl homoserine lactone analogs series III are critical for this series' QSI activity. Specifically, 2-methoxy (11b) and 2-methyl (11h) analogs were more potent than 4-methoxy (11d) and 3-methyl (11i) analogs. Biological evaluation of compounds of series IV revealed that they had weak QSI activity. This clearly shows that the dithiocarbamate group of series III is critical to its QSI activity.

To explore the mechanism of action of active compounds, we tested the effects of analogs $7 \mathbf{b}, \mathbf{8 b}, \mathbf{8 c}, \mathbf{1 1 b}, \mathbf{1 1 f}$ and 11i on the production of virulence factors such as the inhibition of pyocyanin production, reduction of elastase activity and reduction of rhamnolipid production. Meanwhile, we examined the effects of these active compounds on the formation of biofilm and swarming motility. As shown, analogs $\mathbf{7 b}, \mathbf{8 b}, \mathbf{8 c}$, 11b, 11f, 11i and the positive control $\mathbf{C 3 0}$ had no significant effects on the growth of PAO1 at $15 \mu \mathrm{M}$ (Fig. 3A). Thus, we decided to examine their impact on virulence factors at this concentration and found that analogs $\mathbf{7 b}, \mathbf{8 b}, \mathbf{8 c}, \mathbf{1 1 b}, \mathbf{1 1}$ and 11i could inhibit the production of pyocyanin. Specifically, these analogs decreased the production of pyocyanin in PAO1 by $14.2,15.1,27.5,33.0,34.5$ and $30.3 \%$, respectively, at subminimum inhibitory concentrations (sub-MIC), with the inhibitory activity of analogs $\mathbf{8 c}, \mathbf{1 1 b}, \mathbf{1 1}$ and $\mathbf{1 1 i}$ being greater than that of $\mathbf{C 3 0}$ (31.6\%) (Fig. 3B). 11b, 11f and 11i decreased the production of elastase by $14.3,13.7$ and $18.4 \%$, respectively, almost as much as the reduction by $\mathbf{C 3 0}$ (16.5\%) (Fig. 3C). $\mathbf{7 b}, \mathbf{8 b}, \mathbf{8 c}, \mathbf{1 1 b}, \mathbf{1 1 f}, \mathbf{1 1 i}$ and $\mathbf{C 3 0}$ decreased the production of rhamnolipid in PAO1 by 20.5, 22.2, 17.6, 20.8, 28.1, 16.7 and $25.8 \%$, respectively. Overall, 11 was the most potent against virulence factor production compared with C30 (Fig. 3D).

Interestingly, all active compounds also inhibited biofilm formation (Fig. 3E), with this decreased by 28.6, 38.0, 34.1, $35.3,36.2,40.3$ and $28.6 \%$ by $7 \mathbf{b}, \mathbf{8 b}, \mathbf{8 c}, \mathbf{1 1 b}, \mathbf{1 1 f}, \mathbf{1 1} \mathbf{i}$ and C30, respectively. Moreover, analogs $7 \mathbf{b}, \mathbf{1 1 f}$ and $\mathbf{1 1 i}$ showed stronger inhibitory effects on the swarming motility of Pseudomonas than $\mathbf{C 3 0}$ (Fig. 3F), with $\mathbf{1 1 f}$ being the most active. These results verified that analogs $7 \mathbf{b}, \mathbf{8 b}, \mathbf{8 c}, \mathbf{1 1 b}, \mathbf{1 1 f}$ and $\mathbf{1 1 i}$

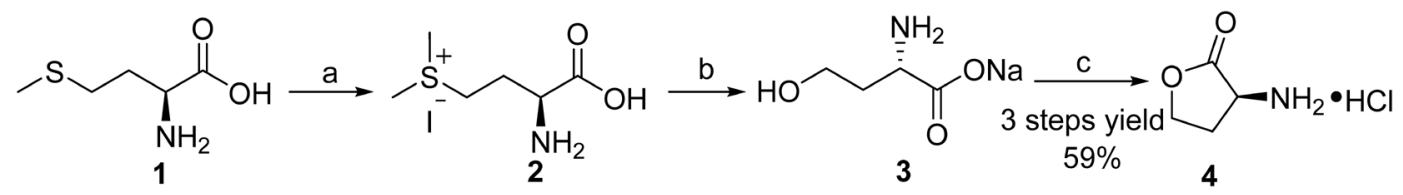

Reagents and conditions: (a) $\mathrm{MeOH} / \mathrm{H}_{2} \mathrm{O}, \mathrm{CH}_{3} \mathrm{I}$, r.t., 20 h; (b) $\mathrm{NaHCO}_{3}$ (aq), r.t. $\rightarrow$ reflux $12 \mathrm{~h}$; (c) $6 \mathrm{M} \mathrm{HCl}, 30 \% \mathrm{H}_{2} \mathrm{O}_{2}$, reflux, 12 h.

Chart 1. Synthesis of L-Homoserine Lactone 4 
<smiles>O=C1OCCC1NCCl</smiles>

4

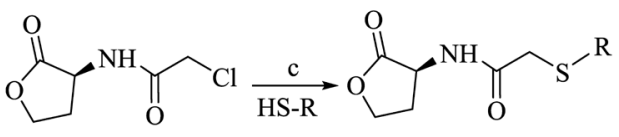

7a-d (Series I)<smiles>[R]CC1=NCCS1</smiles>

$7 \mathbf{a}$<smiles>Cc1ccc(Cl)cc1</smiles>

$7 \mathbf{b}$
5<smiles>Cc1nncs1</smiles><smiles>[14CH3]N[C@@H]1CCOC1=O</smiles>

4

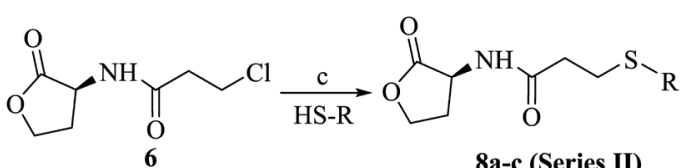

8a-c (Series II)<smiles>[R]C([Y])C1=NCCS1</smiles>

$8 \mathrm{a}$<smiles>Cc1nc2ccccc2s1</smiles>

$8 \mathrm{~b}$<smiles>CC(F)(Cl)c1ccc(Cl)cc1</smiles>

$8 c$

Reagents and conditions: (a) chloroacetyl chloride, $\mathrm{NaHCO}_{3}, \mathrm{CH}_{2} \mathrm{Cl}_{2} \mathrm{H}_{2} \mathrm{O}$ (2:1), r.t., 6h; (b) $\mathrm{NaHCO}_{3}$, 3-chloropropionyl chloride, $\mathrm{CH}_{2} \mathrm{Cl}_{2}: \mathrm{H}_{2} \mathrm{O}(2: 1)$, r.t., 7 h; (c) $\mathrm{K}_{2} \mathrm{CO}_{3}$, acetone, $50^{\circ} \mathrm{C}, 5 \mathrm{~h}$.

Chart 2. Synthesis of Compounds of Series I and II
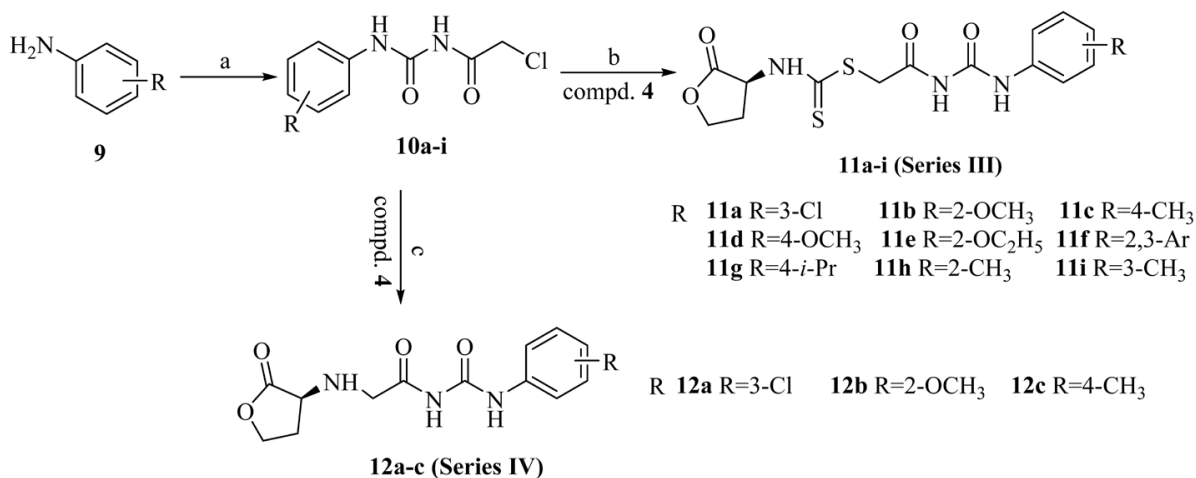

Reagents and conditions: (a) 2-chloroacetamide, oxalamide, $\mathrm{CH}_{2} \mathrm{Cl}_{2}, 0^{\circ} \mathrm{C}$ for $1 \mathrm{~h}$ then $90^{\circ} \mathrm{C}$, reflux, $5 \mathrm{~h}$; (b) $\mathrm{CS}_{2}$, acetone, $\mathrm{Na}_{3} \mathrm{PO}_{4} \cdot 12 \mathrm{H}_{2} \mathrm{O}$, r.t., $6 \mathrm{~h}$; (c) acetonitrile, $\mathrm{NaHCO}_{3}, 75^{\circ} \mathrm{C}$, reflux, $8 \mathrm{~h}$.

Chart 3. Synthesis of Compounds of Series III and IV

Table 1. The Structures and Yields of Compounds of Series I and II

\begin{tabular}{|c|c|c|c|c|c|}
\hline Compd. & $\mathrm{R}$ & Yield & Compd. & $\mathrm{R}$ & Yield \\
\hline $7 \mathbf{a}$ & & $58 \%$ & $8 a$ & & $55 \%$ \\
\hline $7 b$ & & $44 \%$ & $8 b$ & & $50 \%$ \\
\hline $7 c$ & & $53 \%$ & $8 c$ & & $58 \%$ \\
\hline $7 d$ & & $52 \%$ & & & \\
\hline
\end{tabular}

inhibited the bacterial QS system by selectively attenuating its production of virulence factors, especially those that promoted PAO1 biofilm formation.

To further verify the mechanism of action of analogs $\mathbf{7 b}$, $\mathbf{8 b}, \mathbf{8 c}, \mathbf{1 1 b}, \mathbf{1 1 f}$ and 11i, the mRNA expression of QS-related genes rhlI, lasI, pqsA, rhlR, las $R$ and $p q s R$ was analyzed by real-time fluorescence quantitative PCR. These genes are related to the synthesis of QS signal molecules (rhlI, lasI, pqsA)
Table 2. The Structures and Yields of Compounds of Series III and IV

\begin{tabular}{lccccc}
\hline \hline Compd. & $\mathrm{R}$ & Yield & Compd. & $\mathrm{R}$ & Yield \\
\hline $\mathbf{1 1 a}$ & $3-\mathrm{Cl}$ & $44 \%$ & $\mathbf{1 1 g}$ & $4-i-\mathrm{Pr}$ & $49 \%$ \\
$\mathbf{1 1 b}$ & $2-\mathrm{OCH}_{3}$ & $51 \%$ & $\mathbf{1 1 h}$ & $2-\mathrm{CH}_{3}$ & $42 \%$ \\
$\mathbf{1 1 c}$ & $4-\mathrm{CH}_{3}$ & $61 \%$ & $\mathbf{1 1 i}$ & $3-\mathrm{CH}_{3}$ & $55 \%$ \\
$\mathbf{1 1 d}$ & $4-\mathrm{OCH}_{3}$ & $40 \%$ & $\mathbf{1 2 a}$ & $3-\mathrm{Cl}$ & $45 \%$ \\
$\mathbf{1 1 e}$ & $2-\mathrm{OC}_{2} \mathrm{H}_{5}$ & $45 \%$ & $\mathbf{1 2 b}$ & $2-\mathrm{OCH}_{3}$ & $37 \%$ \\
$\mathbf{1 1 f}$ & $2,3-\mathrm{Ar}$ & $47 \%$ & $\mathbf{1 2 c}$ & $4-\mathrm{CH}_{3}$ & $56 \%$ \\
\hline
\end{tabular}

and the regulation of QS proteins $(\operatorname{rhl} R$, las $R, p q s R) .{ }^{3)}$ The results showed that the analogs inhibited the expression of lasI, lasR, pqsA, pqsR, rhlI and rhlR. For example, the expression of lasI was downregulated by 50.5, 32.9, 47.9, 38.9, 55.1, 59.2 and $26.9 \%$ by analogs $7 \mathbf{b}, \mathbf{8 b}, \mathbf{8 c}, \mathbf{1 1 b}, \mathbf{1 1 f}, \mathbf{1 1 i}$ and $\mathbf{C 3 0}$, respectively (Fig. 4A). 8b was almost equipotent with $\mathbf{C 3 0}$ for downregulation of the expressions of lasA, and 11f $(71.0 \%)$ and 11i (64.1\%) were superior to $\mathbf{C 3 0}(58.5 \%$ ) (Fig. 4B). 7b, 8c and 11 were most effective at inhibiting expression of $p q s A$, with 11 downregulating $p q s A$ expression by $67.7 \%$. (Fig. 4C). Analogs 8c, 11b, 11f, 11i and C30 downregulated the expressions of $p q s R$ by $53.5,47.9,72.5,57.5$ and $45.0 \%$, respectively 

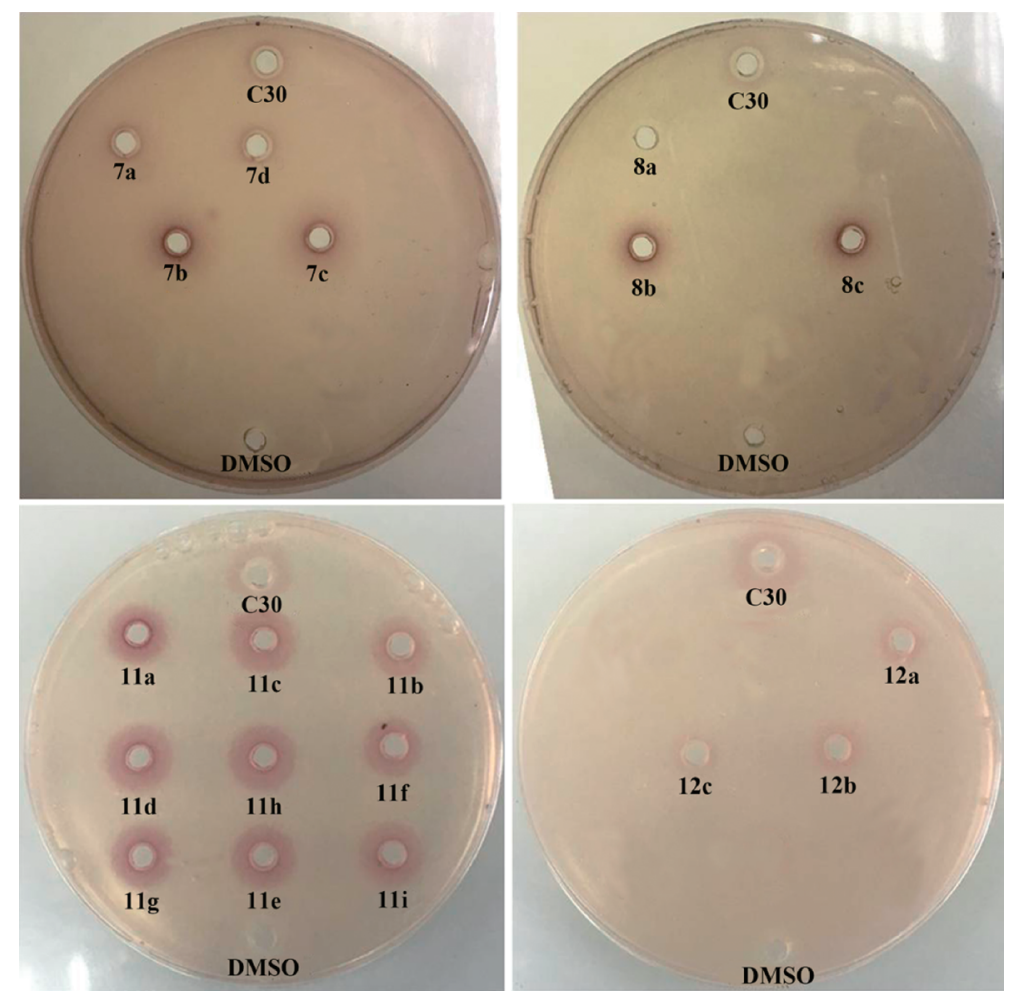

Fig. 2. Inhibitory Effects of All Compounds of Four Series against the P. aeruginosa PAO1 las QS System

The extent of the red turbidity circle represents the degree of inhibition of QS activity by the compound i.e., the larger the circle of turbidity, the greater the inhibitory activity.

(Fig. 4D), but surprisingly only $\mathbf{1 1 f}$ achieved equipotency with C30 for inhibition of rhlI expression (Fig. 4E). Furthermore, 11f and 11i were only slightly more inhibitory of $r h l R$ expression (58.8 and 55.5\%, respectively) than C30 (48.4\%) (Fig. 4F).

In summary, analog 11f was the most potent inhibitor of the expression of most QS-regulated genes in P. aeruginosa PAOI. However, 11f showed more powerful inhibitory activity of lasR, pqsR and rhlR expression than it did of lasI, pqsA and rhlI expression. These results confirmed that active compounds inhibited virulence expression by controlling the expression of related genes (Fig. 4).

\section{Analysis of Molecular Docking Results}

To verify the results of this bioassay evaluation, we used AutoDock molecular simulation software (Molecular modeling was performed using the autodock 4 software from the Scripps Research Institute) to simulate the binding of the active compounds to the receptor protein LasR. ${ }^{38)}$ OdDHL and analogs $\mathbf{7 b}$ and $\mathbf{8 b}$ interacted with Thr-75, Tyr-93 and Ser-129 groups which are located inside the receptor pocket of LasR, via three hydrogen bonds (i.e., $\mathbf{7} \mathbf{b}$ and $\mathbf{8 b}$ each formed one hydrogen bond with each of the three residues) (Figs. 5A-C). 8c interacted with the amino acid residues Tyr-93, Thr-75, Asp-73 and Ser-129 to form four hydrogen bonds (Fig. 5D); 11b formed two hydrogen bonds by interacting with Asp-73 and Ser-129 (Fig. 5E); 11f linked with Ser-129 and Arg-61 to form three hydrogen bonds (Fig. 5F); 11i interacted with Tyr-56, Tyr-47 and Ser-129 via three hydrogen bonds (Fig. 5G).

The fact that 11f was the most potent compound and also the only analog that interacted with Arg-61 suggested that Arg-61 may be more important for QS than other amino acid residues in the active site of LasR. Thus, the molecular docking results correlated well with the biological evaluation results.

\section{Conclusion}

In conclusion, we have designed and synthesized four series of novel L-homoserine lactone analogs and evaluated their inhibitory activity against QS in $P$. aeruginosa. The results indicated that $\mathbf{7 b}$ and $\mathbf{7 c}$ of series $\mathbf{I}$ and $\mathbf{8 b}$ and $\mathbf{8 c}$ of series II, representing L-homoserine lactone analogs with benzothiazolyl and 4-chlorophenyl substituents, respectively, showed greater inhibitory activity against CV026 and PAO1 than 7a, 7d and 8a, with 4,5-dihydro-thiazol or 1,3,4-thiadiazole substituents. In addition, most compounds of series III with a sidechain comprising a phenylurea and dithiocarbamate group exhibited remarkable inhibition of QS in CV026 and PAO1. Compounds of series IV, with a sidechain comprising only a phenylurea group, had weak QSI activity. These results indicated that the dithiocarbamate group was critical to the QSI activity of series III.

The results of mechanism of action studies verified that analogs $7 \mathbf{b}, 8 \mathbf{b}, 8 \mathbf{c}, 11 \mathbf{b}, 11 \mathbf{f}$ and $11 \mathbf{i}$ inhibited the $P$. aeruginosa QS system by selectively attenuating the expression of virulence factors, especially biofilm formation by PAO1. The activity of compound 11f was superior to that of all other analogs, and the results of molecular docking indicated that $11 \mathbf{f}$ competed with OdDHL to bind with LasR. This 11f-LasR interaction inhibited the expression of the las system genes, PQS system genes and $r h l$ system-related genes, thereby inhibiting the production of virulence factors and the formation of PAO1 biofilm.

Our research has enriched the chemical space around Lhomoserine lactones, and afforded a new lead compound (11f) 

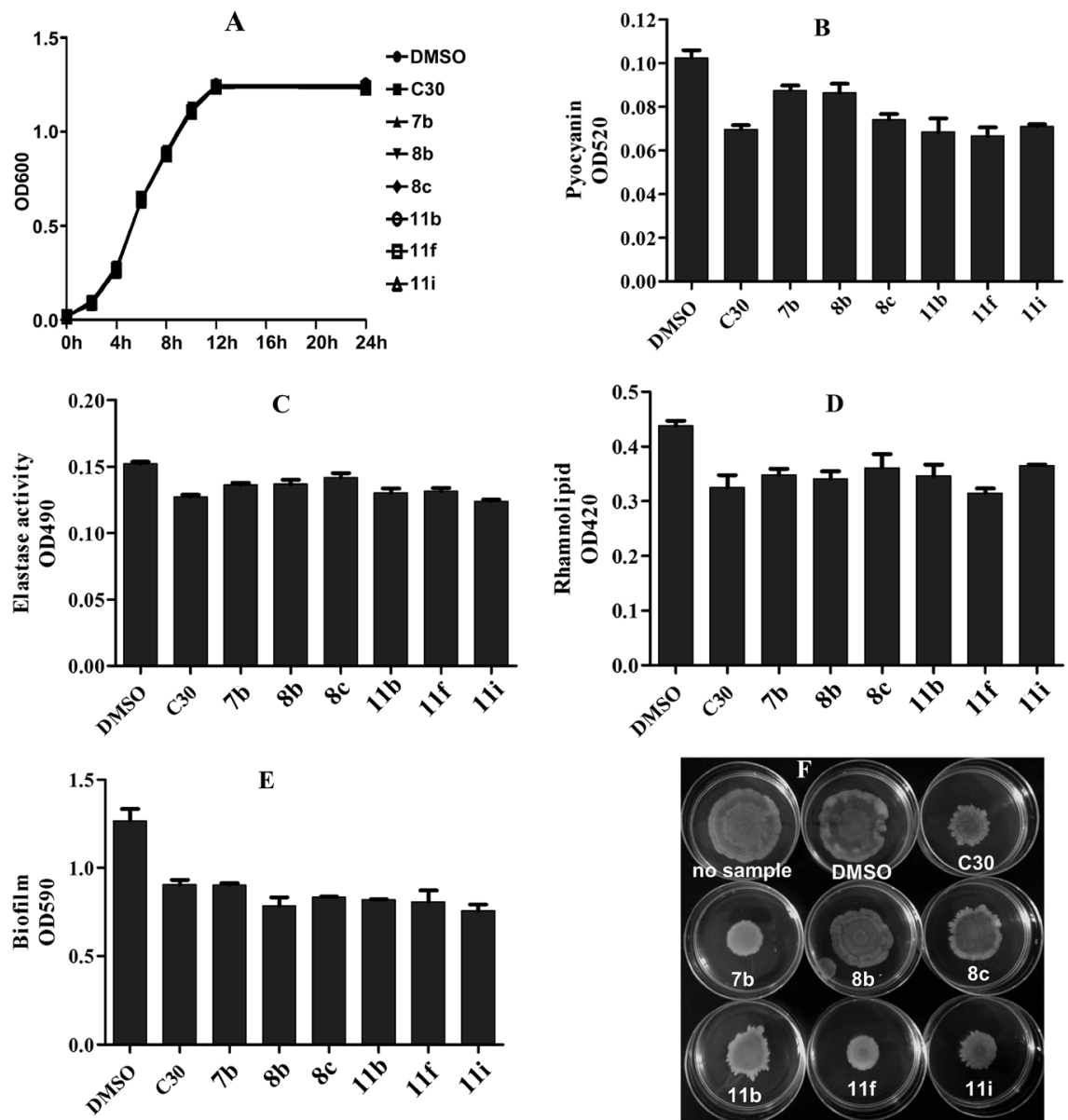

Fig. 3. (A) Growth Curve Analysis of Paeruginosa PAO1 Treated with Active Compounds at Sub-MICs $(15 \mu \mathrm{M})$

(B) Effects of active compounds on pyocyanin production. (C) Effects of active compounds on elastase activity. (D) Effects of active compounds on rhamnolipid production. (E) Effects of active compounds on biofilm formation. (F) Effects of active compounds on swarming motility. C30 is used as a positive control, and DMSO is used as a negative control.

for the development of QS inhibitors as antibacterial agents with less likelihood of triggering the development of resistance. We expect that further investigation and expansion of the SAR of $\mathbf{1 1 f}$ will afford more efficient and highly selective QSIs for antibacterial drug development.

\section{Experimental}

General Remarks All chemical reagents and solvents were purchased from commercial sources and used without further purification. ${ }^{1} \mathrm{H}-\mathrm{NMR}(400 \mathrm{MHz})$ and ${ }^{13} \mathrm{C}-\mathrm{NMR}$ spectra $(100 \mathrm{MHz})$ were recorded on a Bruker (DPX-400) spectrometer. High resolution (HR)-MS were recorded on a Waters Micromass Q-Tof Micromass spectrometer by electrospray ionization (ESI). Melting points were determined on X-5 Microdigital melting point ( $\mathrm{mp}$ ) apparatus and are reported uncorrected.

Synthesis of L-Homoserine Lactone Hydrochloride (4) L-Homoserine lactone hydrochloride (4) was efficiently synthesized from methionine following our previously reported methods. $^{28)}$

L-Homoserine lactone hydrochloride 4, white solid, (3 steps, yield $59 \%), \mathrm{mp} 218-220^{\circ} \mathrm{C},[\alpha]_{\mathrm{D}}^{20}-27.5^{\circ},(c 0.2 \text {, water })^{30)}$; ${ }^{1} \mathrm{H}-\mathrm{NMR}\left(400 \mathrm{MHz}\right.$, dimethyl sulfoxide (DMSO)- $d_{6}$ ) $\delta: 9.04$ (s, $\left.3 \mathrm{H}, \mathrm{NH}_{2} \cdot \mathrm{HCl}\right), 4.45\left(\mathrm{t}, J=8.8 \mathrm{~Hz}, 1 \mathrm{H},-\mathrm{O}-\mathrm{CH}_{2}\right), 4.37-4.21(\mathrm{~m}$, $\left.2 \mathrm{H},-\mathrm{O}-\mathrm{CH}_{2},-\mathrm{CH}-\mathrm{CO}\right), 2.62-2.51\left(\mathrm{~m}, 1 \mathrm{H},-\mathrm{O}-\mathrm{CH}_{2}-\mathrm{CH}_{2}-\mathrm{CH}\right)$,

\subsection{2-2.27 (m, 1H, - O- $\left.\mathrm{CH}_{2}-\mathrm{CH}_{2}-\mathrm{CH}\right)$}

General Procedure for the Synthesis of Compounds 5 and 6 Compounds 5 and $\mathbf{6}$ were efficiently synthesized from L-homoserine lactone hydrochloride $\mathbf{4}$ following our previously reported methods. ${ }^{39)}$ The acyl group of $\mathbf{5}$ and $\mathbf{6}$ was introduced by condensation with chloroacetyl chloride and 3-chloropropionyl chloride, respectively.

(S)-2-Chloro- $N$-(2-carbonyl Tetrahydrofuran-3-yl)acetamide 5

White solid: (TLC acetone:petroleum ether 2:1), (yield $68.2 \%)$, mp $121-122^{\circ} \mathrm{C}$; ${ }^{1} \mathrm{H}-\mathrm{NMR} \quad\left(400 \mathrm{MHz}\right.$, DMSO- $\left.d_{6}\right)$ $\delta: 8.76(\mathrm{~d}, J=8.0 \mathrm{~Hz}, 1 \mathrm{H},-\mathrm{CO}-\mathrm{NH}), 4.63(\mathrm{dd}, J=20.0 \mathrm{~Hz}$, $\left.J=8.0 \mathrm{~Hz}, 1 \mathrm{H},-\mathrm{O}-\mathrm{CH}_{2}\right), 4.35(\mathrm{t}, J=8.0 \mathrm{~Hz}, 1 \mathrm{H},-\mathrm{CH}-\mathrm{NH})$, $4.21\left(\mathrm{dd}, J=20.0 \mathrm{~Hz}, J=8.0 \mathrm{~Hz}, 1 \mathrm{H},-\mathrm{O}-\mathrm{CH}_{2}\right), 4.1 \overline{\mathrm{s}}, 2 \mathrm{H}$, $\left.-\mathrm{CH}_{2}-\mathrm{Cl}\right), 2.44-2.36\left(\mathrm{~m}, 1 \mathrm{H},-\mathrm{O}-\mathrm{CH}_{2}-\mathrm{CH}_{2}-\overline{\mathrm{CH}}\right), 2.24-2.15(\mathrm{~m}$, $\left.\overline{1 \mathrm{H}},-\mathrm{O}-\mathrm{CH}_{2}-\mathrm{CH}_{2}-\mathrm{CH}-\right)$.

(S)-2-Chloro- $N$-(2-carbonyl Tetrahydrofuran-3-yl)propylamide 6

White solid (TLC: acetone:petroleum ether 2:1), (yield $64.5 \%), \quad m p 127-129^{\circ} \mathrm{C} ; \quad{ }^{1} \mathrm{H}-\mathrm{NMR} \quad\left(400 \mathrm{MHz}, \quad \mathrm{DMSO}-d_{6}\right)$ $\delta: 8.50(\mathrm{~d}, J=7.8 \mathrm{~Hz}, 1 \mathrm{H},-\mathrm{CO}-\mathrm{NH}), 4.52(\mathrm{dt}, J=10.8 \mathrm{~Hz}$, $\left.8.9 \mathrm{~Hz}, 1 \mathrm{H},-\mathrm{O}-\mathrm{CH}_{2}\right), 4.28(\mathrm{td}, J=8.8,1.8 \mathrm{~Hz}, 1 \mathrm{H},-\mathrm{CH}-\mathrm{NH})$, 4.15 (ddd, $\left.J=1 \overline{0.4}, 8.8,6.5 \mathrm{~Hz}, 1 \mathrm{H},-\mathrm{O}-\mathrm{CH}_{2}\right), 3.73-3.69(\mathrm{~m}$, $\left.2 \mathrm{H},-\mathrm{CH}_{2}-\mathrm{Cl}\right), 2.56\left(\mathrm{td}, J=6.2,1.7 \mathrm{~Hz}, \overline{2 \mathrm{H}},-\mathrm{CH}_{2}-\mathrm{CH}_{2}-\mathrm{Cl}\right)$, $2.39-\overline{2.31}\left(\mathrm{~m}, 1 \mathrm{H},-\mathrm{O}-\mathrm{CH}_{2}-\mathrm{CH}_{2}-\mathrm{CH}\right), 2.12-2.01 \overline{(\mathrm{m}}, 1 \mathrm{H},-\mathrm{O}-$ $\left.\mathrm{CH}_{2}-\mathrm{CH}_{2}-\mathrm{CH}\right)$. 

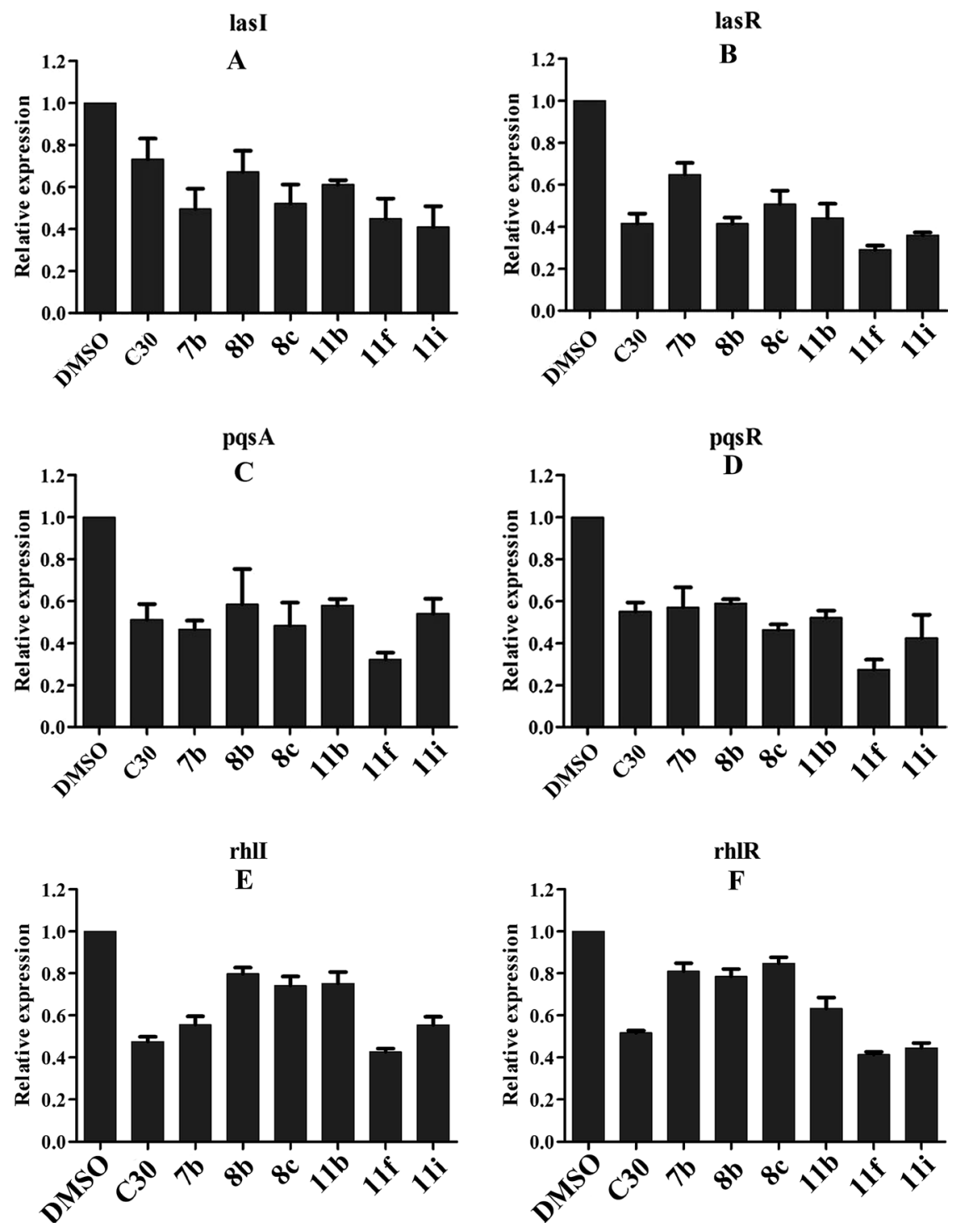

Fig. 4. Inhibition of QS-regulated Gene ((A)-(F)) Expression in P. aeruginosa PAO1 by Active Compounds

(A) lasI. (B) lasR. (C) pqsA. (D) pqsR. (E) rhli. (F) rhlR.

General Procedure for the Synthesis of Compounds $7 \mathbf{a}-\mathbf{d}$ A solution of HS- $\mathrm{R}_{2}(0.92 \mathrm{mmol})$ and $\mathrm{K}_{2} \mathrm{CO}_{3}(120 \mathrm{mg})$ in acetone was added to compound $\mathbf{5}(0.84 \mathrm{mmol})$. After $5 \mathrm{~h}$ stirring at $50^{\circ} \mathrm{C}$, the solvent was removed under vacuum, and the resulting residue was extracted with ethyl acetate and water. The organic layer was dried over $\mathrm{MgSO}_{4}$ and evaporated under vacuum, and the resulting residue was purified by column chromatography, affording white solid $7 \mathbf{a}-\mathbf{d}$.

(S)-2-((4,5-Dihydrothiazol-2-yl)thio)- $N$-(2-oxotetrahydrofuran-3yl) Cetamide $7 \mathbf{a}$

White solid (TLC: petroleum ether:EtOAc 1:6), (yield $58 \%$ ), mp $114-116^{\circ} \mathrm{C} ;{ }^{1} \mathrm{H}-\mathrm{NMR}\left(400 \mathrm{MHz}, \mathrm{DMSO}-d_{6}\right) \delta: 8.65$ (d, $J=7.8 \mathrm{~Hz}, 1 \mathrm{H},-\mathrm{CO}-\mathrm{NH}-), 4.60-4.53\left(\mathrm{~m}, 1 \mathrm{H},-\mathrm{O}-\mathrm{CH}_{2}-\right)$, $4.34(\mathrm{td}, J=8.8,1.7 \mathrm{~Hz}, \overline{1 \mathrm{H}},-\mathrm{CH}-\mathrm{NH}-), 4.20$ (ddd, $J \overline{=10.4}$, $\left.8.8,6.5 \mathrm{~Hz}, 1 \mathrm{H},-\mathrm{O}-\mathrm{CH}_{2}-\right), 4.12 \overline{(\mathrm{t}}, J=8.0 \mathrm{~Hz}, 2 \mathrm{H},-\mathrm{CO}-\mathrm{CH}_{2}-$ S-), 3.94-3.86 (m, $\left.\overline{2 \mathrm{H}},-\mathrm{CH}_{2}-\mathrm{S}-\right), 3.46(\mathrm{t}, J=8.0 \mathrm{~Hz}, \overline{2 \mathrm{H}}$, $\left.-\mathrm{CH}_{2}-\mathrm{N}-\right)$, 2.44-2.36 (m, $\left.\overline{1 \mathrm{H}},-\mathrm{O}-\mathrm{CH}_{2}-\mathrm{CH}_{2}-\mathrm{CH}-\right), 2.18-2.08$ $\left(\overline{\mathrm{m},} 1 \mathrm{H},-\mathrm{O}-\mathrm{CH}_{2}-\mathrm{CH}_{2}-\mathrm{CH}-\right) .{ }^{13} \mathrm{C}-\mathrm{NMR}\left(\overline{100} \mathrm{MHz}, \mathrm{DMSO}-d_{6}\right)$ $\delta$ : 174.9, 166.8, $1 \overline{62.6}, 65.3,63.8,48.29,35.55,35.42,28.11$. HRESI-MS $m / z$ calcd for $[\mathrm{M}+\mathrm{H}]^{+} \mathrm{C}_{9} \mathrm{H}_{12} \mathrm{~N}_{2} \mathrm{O}_{3} \mathrm{~S}_{2}: 261.0362$. Found: 261.0368 .
(S)-2-(Benzo[d]thiazol-2-ylthio)- $N$-(2-oxotetrahydrofuran-3yl)acetamide $\mathbf{7 b}$

White solid (TLC: petroleum ether:EtOAc 1:3), (yield 44\%), mp 133-135 ${ }^{\circ} \mathrm{C} ;{ }^{1} \mathrm{H}-\mathrm{NMR}\left(400 \mathrm{MHz}, \mathrm{DMSO}-d_{6}\right) \delta: 8.88$ (d, $J=7.8 \mathrm{~Hz}, 1 \mathrm{H},-\mathrm{CO}-\mathrm{NH}-), 8.02$ (d, $J=8.0 \mathrm{~Hz}, 1 \mathrm{H}, \mathrm{Ar}-\mathrm{H}-)$, 7.84 (d, $J=8.1 \mathrm{~Hz}, 1 \mathrm{H}, \overline{\mathrm{Ar}-\mathrm{H}-}), 7.49-7.45$ (m, 1H, Ar-H-), 7.37 (m, 1H, Ar-H-), 4.63 (dt, $\left.J=10.7,8.8 \mathrm{~Hz}, 1 \mathrm{H},-\mathrm{O}-\mathrm{CH}_{2}-\right), 4.35$ (td, $J=8.8,1.5 \mathrm{~Hz}, 1 \mathrm{H},-\mathrm{CH}-\mathrm{NH}-), 4.25-4.17$ (m, 33,$-\mathrm{O}-\mathrm{CH}_{2}-$, $\left.-\mathrm{CH}_{2}-\mathrm{S}-\right), 2.46-2.39\left(\mathrm{~m}, \overline{\mathrm{H}},-\mathrm{O}-\mathrm{CH}_{2}-\mathrm{CH}_{2}-\mathrm{CH}-\right), 2.17(\mathrm{~m}, 1 \mathrm{H}$,

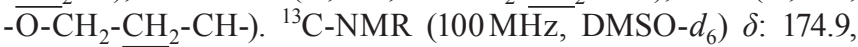
$166.6,165.9,152.5,134.8,126.4,124.5,121.8,121.1,65.3,48.4$, 36.2 , 28.1. HRESI-MS $m / z$ calcd for $[\mathrm{M}+\mathrm{Na}]^{+} \mathrm{C}_{13} \mathrm{H}_{12} \mathrm{~N}_{2} \mathrm{O}_{3} \mathrm{~S}_{2}$ : 331.0182. Found: 331.0198.

(S)-2-((4-Chlorophenyl)thio)- $N$-(2-oxotetrahydrofuran-3-yl)acetamide $7 \mathrm{c}$

White solid (TLC: petroleum ether:EtOAc 1:3), (yield 53\%), mp $139-141^{\circ} \mathrm{C}$; ${ }^{1} \mathrm{H}-\mathrm{NMR}\left(400 \mathrm{MHz}, \mathrm{DMSO}-d_{6}\right) \delta: 8.69$ (d, $J=7.8 \mathrm{~Hz}, 1 \mathrm{H},-\mathrm{CO}-\mathrm{NH}-), 7.40-7.36$ (m, 4H, Ar-H-), 4.57 (dt, $\left.J=10.9,8.9 \mathrm{~Hz}, 1 \mathrm{H},-\mathrm{O}-\mathrm{CH}_{2}-\right), 4.34$ (td, $J=8.8,1.5 \mathrm{~Hz}$, $1 \mathrm{H},-\mathrm{CH}-\mathrm{NH}-$ ), 4.20 (ddd, $J=\overline{10.4}, 8.8,6.5 \mathrm{~Hz}, 1 \mathrm{H},-\mathrm{O}-\mathrm{CH}_{2}-$ ),

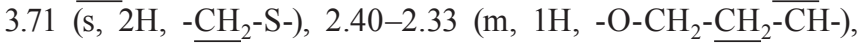



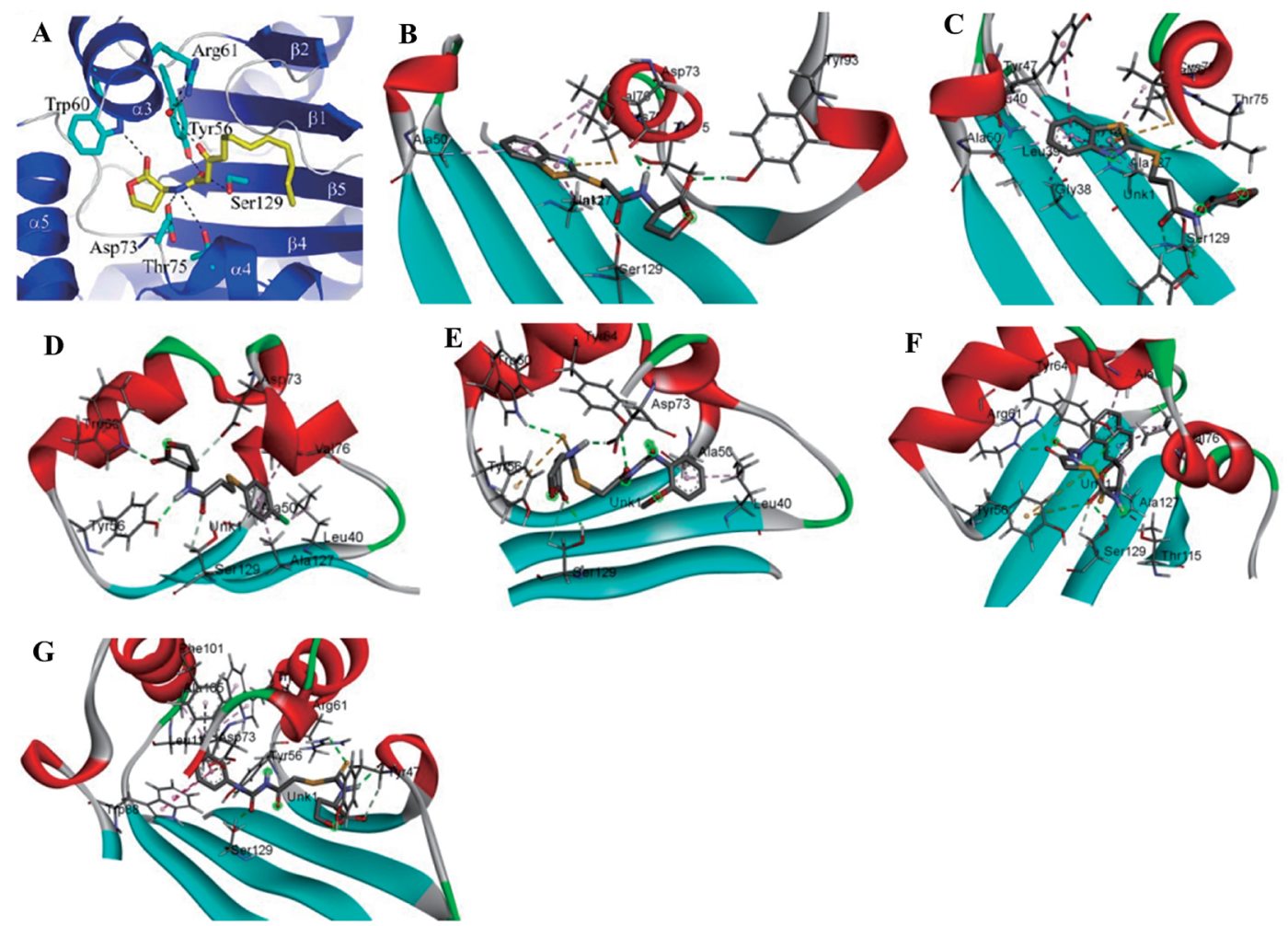

Fig. 5. The Results of the Docking Pose of OdDHL (A) ${ }^{38)}$ and Compounds $7 \mathbf{b}(B), \mathbf{8 b}(\mathrm{C}), \mathbf{8 c}(\mathrm{D}), \mathbf{1 1 b}(\mathrm{E}), \mathbf{1 1}(\mathrm{F})$ and $\mathbf{1 1 i}(\mathrm{G})$ with the Receptor Protein LasR

Hydrogen bonds are shown as green balls.

$2.11\left(\mathrm{~m}, 1 \mathrm{H},-\mathrm{O}-\mathrm{CH}_{2}-\mathrm{CH}_{2}-\mathrm{CH}-\right) .{ }^{13} \mathrm{C}-\mathrm{NMR}(100 \mathrm{MHz}, \mathrm{DMSO}-$ $\left.d_{6}\right) \delta: 174.9,167.9,13 \overline{4.9}, 130.7,129.9,128.8,65.3,48.2,36.2$, 28.0. HRESI-MS $\mathrm{m} / \mathrm{z}$ calcd for $[\mathrm{M}+\mathrm{Na}]^{+} \mathrm{C}_{12} \mathrm{H}_{12} \mathrm{ClNO}_{3} \mathrm{~S}$ : 308.0124. Found: 308.0117.

(S)-2-((1,3,4-Thiadiazol-2-yl)thio)- $N$-(2-oxotetrahydrofuran-3yl)acetamide 7d

White solid (TLC: acetone:EtOAc 1:6), (yield 52\%), mp $96-97^{\circ} \mathrm{C} ;{ }^{1} \mathrm{H}-\mathrm{NMR}\left(400 \mathrm{MHz}, \mathrm{DMSO}-d_{6}\right) \delta$ : 9.52 (s, $1 \mathrm{H},-\mathrm{CH}-\mathrm{N}-), 8.84$ (d, J=7.8 Hz, 1H, -CO-NH-), 4.64-4.57 $\left(\mathrm{m}, 1 \overline{\mathrm{H}},-\mathrm{O}-\mathrm{CH}_{2}-\right), 4.35(\mathrm{td}, J=8.8,1.7 \mathrm{~Hz}, \overline{1 \mathrm{H}},-\mathrm{CH}-\mathrm{NH}-)$, $4.24-4.18\left(\mathrm{~m}, 1 \mathrm{H},-\mathrm{O}-\mathrm{CH}_{2}-\right), 4.15\left(\mathrm{~d}, J=2.5 \mathrm{~Hz}, 2 \mathrm{H},-\mathrm{CH}_{2}-\mathrm{S}-\right.$ ), 2.45-2.38 (m, 1H, -O- $\left.\mathrm{CH}_{2}-\mathrm{CH}_{2}-\mathrm{CH}-\right), 2.20-2.09(\mathrm{~m}, 1 \mathrm{H}$, -O- $\left.\mathrm{CH}_{2}-\mathrm{CH}_{2}-\mathrm{CH}-\right) .{ }^{13} \mathrm{C}-\mathrm{NMR}\left(\overline{100} \mathrm{MHz}, \mathrm{DMSO}-d_{6}\right) \delta$ : 174.8 , $166.5,164.9,154.2,65.3,48.4,37.0,28.1$. HRESI-MS $\mathrm{m} / \mathrm{z}$ calcd for $[\mathrm{M}+\mathrm{Na}]^{+} \mathrm{C}_{8} \mathrm{H}_{9} \mathrm{~N}_{3} \mathrm{O}_{3} \mathrm{~S}_{2}: 281.9978$. Found: 281.9977.

General Procedure for the Synthesis of Compounds 8a-c A solution of the mercapto compound $(0.92 \mathrm{mmol})$ and $\mathrm{K}_{2} \mathrm{CO}_{3}$ $(120 \mathrm{mg})$ in acetone was added to compound $6(0.78 \mathrm{mmol})$. After stirring at $50^{\circ} \mathrm{C}$ for $5 \mathrm{~h}$, the solvent was removed under vacuum and the resulting was extracted with ethyl acetate and water. The organic layer was dried over $\mathrm{MgSO}_{4}$ and evaporated under vacuum to give a residue, which was then purified by column chromatography, affording a white solid $(\mathbf{8 a}-\mathbf{c})$.

$(S)-3-((4,5-D i h y d r o t h i a z o l-2-y l) t h i o)-N$-(2-oxotetrahydrofuran-3yl)propanamid 8a

White solid (TLC: petroleum ether:EtOAc 1:10), (yield $55 \%$ ), mp $128-130{ }^{\circ} \mathrm{C}$; ${ }^{1} \mathrm{H}-\mathrm{NMR}\left(400 \mathrm{MHz}, \mathrm{DMSO}-d_{6}\right) \delta: 8.59$ (d, $J=7.9 \mathrm{~Hz}, 1 \mathrm{H},-\mathrm{CO}-\mathrm{NH}-), 4.55$ (dt, $J=10.8,8.8 \mathrm{~Hz}, 1 \mathrm{H}$, $\left.-\mathrm{O}-\mathrm{CH}_{2}-\right), 4.35$ (td, $\left.J=8 \overline{8.7} 1.5 \mathrm{~Hz}, 1 \mathrm{H},-\mathrm{CH}-\mathrm{NH}-\right), 4.24-4.19$ $\left(\mathrm{m}, \overline{1 \mathrm{H}},-\mathrm{O}-\mathrm{CH}_{2}-\right), 4.14\left(\mathrm{t}, J=7.9 \mathrm{~Hz}, 2 \overline{\mathrm{H}},-\mathrm{CH}_{2}-\mathrm{N}-\right), 3.88(\mathrm{t}$, $\left.J=6.9 \mathrm{~Hz}, 2 \overline{\mathrm{H}},-\mathrm{CH}_{2}-\mathrm{CH}_{2}-\mathrm{N}-\right), 3.33-3.29\left(\mathrm{~m}, 2 \mathrm{H},-\mathrm{CH}_{2}-\mathrm{S}-\right)$,
2.53-2.50 (m, 2H, $\left.-\mathrm{CH}_{2}-\mathrm{CH}_{2}-\mathrm{S}-\right), 2.43-2.36\left(\mathrm{~m}, 1 \mathrm{H},-\mathrm{O}-\mathrm{CH}_{2}-\right.$ $\left.\mathrm{CH}_{2}-\mathrm{CH}-\right), 2.23-2.12\left(\mathrm{~m}, 1 \mathrm{H},-\mathrm{O}-\mathrm{CH}_{2}-\mathrm{CH}_{2}-\mathrm{CH}-\right) .{ }^{13} \mathrm{C}-\mathrm{NMR}$ $\left(100 \mathrm{MHz}, \mathrm{DMSO}-d_{6}\right) \delta$ : 195.0, 175.2, $1 \overline{70.0}, 65.3,57.3,48.0$, 45.1, 32.2, 28.0, 27.1. HRESI-MS $\mathrm{m} / z$ calcd for $[\mathrm{M}+\mathrm{Na}]^{+}$ $\mathrm{C}_{10} \mathrm{H}_{14} \mathrm{~N}_{2} \mathrm{O}_{3} \mathrm{~S}_{2}$ : 297.0338. Found: 297.0331 .

(S)-3-(Benzo[d]thiazol-2-ylthio)- $N$-(2-oxotetrahydrofuran-3yl)propanamide $\mathbf{8 b}$

White solid (TLC: petroleum ether:EtOAc 1:4), (yield $50 \%)$ mp $137-138^{\circ} \mathrm{C}$; ${ }^{1} \mathrm{H}-\mathrm{NMR} \quad\left(400 \mathrm{MHz}\right.$, DMSO- $\left.d_{6}\right) \quad \delta$ : $8.53(\mathrm{~d}, J=7.9 \mathrm{~Hz}, 1 \mathrm{H},-\mathrm{CO}-\mathrm{NH}-), 8.01$ (d, $J=8.0 \mathrm{~Hz}, 1 \mathrm{H}$, Ar-H-), 7.88 (d, $J=8.0 \mathrm{~Hz}, \overline{1 \mathrm{H},}$ Ar-H-) $7.49-7.45$ (m, $1 \mathrm{H}$, Ar-H-), 7.39-7.35 (m, 1H, Ar-H-), 4.59 (dt, $J=10.7,8.8 \mathrm{~Hz}$, $\left.1 \mathrm{H},-\mathrm{O}-\mathrm{CH}_{2}-\right), 4.35$ (td, $\left.J=8.8,1.6 \mathrm{~Hz}, 1 \mathrm{H},-\mathrm{CH}-\mathrm{NH}-\right), 4.22$ (ddd, $\left.J=10.3,8.8,6.5 \mathrm{~Hz}, 1 \mathrm{H},-\mathrm{O}-\mathrm{CH}_{2}-\right), 3.54(\mathrm{t}, J=6.9 \mathrm{~Hz}$, $\left.2 \mathrm{H},-\mathrm{CH}_{2}-\mathrm{S}-\right), 2.78-2.69\left(\mathrm{~m}, 2 \mathrm{H},-\overline{\mathrm{CH}}_{2}-\mathrm{CH}_{2}-\mathrm{S}-\right), 2.46-2.38$ (m, $\left.1 \overline{\mathrm{H}},-\mathrm{O}-\mathrm{CH}_{2}-\mathrm{CH}_{2}-\mathrm{CH}-\right), 2.14\left(\mathrm{~m}, \overline{\mathrm{1H}},-\mathrm{O}-\mathrm{CH}_{2}-\mathrm{CH}_{2}-\mathrm{CH}-\right)$. ${ }^{13} \mathrm{C}-\mathrm{NMR}\left(100 \mathrm{MHz}, \mathrm{DMSO}-d_{6}\right) \delta$ : 175.7, $170.5,16 \overline{7.0}, 153.2$, 135.0, 126.8, 124.9, 122.3, 121.6, 65.8, 48.5, 35.0, 28.9, 28.8. HRESI-MS $m / z$ calcd for $[\mathrm{M}+\mathrm{Na}]^{+} \mathrm{C}_{14} \mathrm{H}_{14} \mathrm{~N}_{2} \mathrm{O}_{3} \mathrm{~S}_{2}: 345.0338$. Found: 345.0346 .

(S)-3-((4-Chlorophenyl)thio)- $N$-(2-oxotetrahydrofuran-3-yl)propanamide 8c

White solid (TLC: petroleum ether:EtOAc 1:3), (yield $58 \%$ ), mp $88-89^{\circ} \mathrm{C} ;{ }^{1} \mathrm{H}-\mathrm{NMR}\left(400 \mathrm{MHz}, \mathrm{DMSO}-d_{6}\right) \delta: 8.47(\mathrm{~d}$, $J=7.9 \mathrm{~Hz}, 1 \mathrm{H},-\mathrm{CO}-\mathrm{NH}-), 7.41-7.35$ (m, 4H, Ar-H-), 4.57 (dt, $\left.J=10.8,8.8 \mathrm{~Hz}, 1 \mathrm{H},-\mathrm{O}-\mathrm{CH}_{2}-\right), 4.35(\mathrm{td}, J=8.8,1.7 \mathrm{~Hz}, 1 \mathrm{H}$, -CH-NH-), 4.21 (ddd, $\left.J=\overline{10.4}, 8.7,6.5 \mathrm{~Hz}, 1 \mathrm{H},-\mathrm{O}-\mathrm{CH}_{2}-\right), 3.16$ (t, $\left.J=7.2 \mathrm{~Hz}, 2 \mathrm{H},-\mathrm{CH}_{2}-\mathrm{S}-\right), 2.46\left(\mathrm{t}, J=7.3 \mathrm{~Hz}, 2 \mathrm{H},-\overline{\mathrm{CH}}_{2}-\mathrm{CH}_{2}-\right.$ S-), 2.42-2.36 (m, $\left.\overline{1 \mathrm{H}},-\mathrm{O}-\mathrm{CH}_{2}-\mathrm{CH}_{2}-\mathrm{CH}-\right), 2.17-2.06(\mathrm{~m}, 1 \mathrm{H}$, $\left.-\mathrm{O}-\mathrm{CH}_{2}-\mathrm{CH}_{2}-\mathrm{CH}-\right) .{ }^{13} \mathrm{C}-\mathrm{NMR}\left(100 \mathrm{MHz}, \mathrm{DMSO}-d_{6}\right) \delta$ : 175.2 , $170.1,135.0,130.4,129.9,129.0,65.3,47.9,34.5,28.3,28.0$. 
HRESI-MS $m / z$ calcd for $[\mathrm{M}+\mathrm{Na}]^{+} \mathrm{C}_{13} \mathrm{H}_{14} \mathrm{ClNO}_{3} \mathrm{~S}: 322.0275$. Found: 322.0285 .

General Procedure for the Synthesis of Compounds 11a-i A solution of compound $4(150 \mathrm{mg}, 1.09 \mathrm{mmol})$ and $\mathrm{Na}_{3} \mathrm{PO}_{4} \cdot 12 \mathrm{H}_{2} \mathrm{O}(620 \mathrm{mg}, 1.63 \mathrm{mmol})$ in acetone was added to $\mathrm{CS}_{2}(160 \mu \mathrm{L})$ and stirred for $2 \mathrm{~h}$ at room temperature. The resulting solution was added to compounds $10 \mathrm{a}-\mathbf{i}(1.20 \mathrm{mmol})$ to react for $6 \mathrm{~h}$ at room temperature. The solvent was removed under vacuum, extracted with ethyl acetate and water. The organic layer was dried over $\mathrm{MgSO}_{4}$ and evaporated under vacuum to give the residue, which was then purified by column chromatography, affording a white solid (11a-i).

2-(3-(3-Chlorophenyl)ureido)-2-oxoethyl( $S$ )-(2-oxotetrahydrofuran-3-yl)carbamodithi-oate 11a

White solid (TLC: petroleum ether:EtOAc 1:1), (yield $44 \%)$ mp $140-142^{\circ} \mathrm{C} ;{ }^{1} \mathrm{H}-\mathrm{NMR}\left(400 \mathrm{MHz}\right.$, DMSO- $\left.d_{6}\right) \delta: 11.04$ (s, $1 \mathrm{H},-\mathrm{CO}-\mathrm{NH}-\mathrm{CO}-), 10.51$ (d, $J=7.9 \mathrm{~Hz}, 1 \mathrm{H},-\mathrm{CS}-\mathrm{NH}-$ ), 10.40 (s, 1H, $\overline{\mathrm{Ar}-\mathrm{NH}}-\mathrm{CO}-), 7.79$ (t, $J=1.9 \mathrm{~Hz}, 1 \mathrm{H}, \mathrm{Ar}-\mathrm{H}), 7.41$ $(\mathrm{d}, J=8.9 \mathrm{~Hz}, 1 \overline{\mathrm{H}, \mathrm{Ar}}-\mathrm{H}), 7.34(\mathrm{t}, J=8.0 \mathrm{~Hz}, 1 \mathrm{H}, \mathrm{Ar}-\mathrm{H}), 7.15$ (dd, $J=7.8,0.8 \mathrm{~Hz}, 1 \mathrm{H}, \mathrm{Ar}-\mathrm{H}), 5.50(\mathrm{dt}, J=10.9,8.6 \mathrm{~Hz}, 1 \mathrm{H}$, $-\mathrm{O}-\mathrm{CH}_{2}-$ ), 4.40 (t, $\left.J=8.4 \mathrm{~Hz}, 1 \mathrm{H},-\mathrm{CH}-\mathrm{NH}-\right), 4.33-4.27$ (m, $\left.3 \mathrm{H},-\mathrm{O}-\mathrm{CH}_{2}-,-\mathrm{CH}_{2}-\mathrm{S}-\right), 2.59-2.55\left(\mathrm{~m}, 1 \mathrm{H},-\mathrm{O}-\mathrm{CH}_{2}-\mathrm{CH}_{2}-\mathrm{CH}-\right)$,

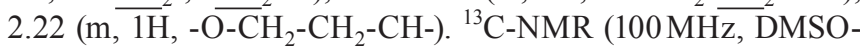
$\left.d_{6}\right) \delta: 197.2,173.5,170.0,150.4,136.5,128.8,127.4,121.4$, $65.5,54.7,30.7,27.9$. HRESI-MS $\mathrm{m} / \mathrm{z}$ calcd for $[\mathrm{M}+\mathrm{Na}]^{+}$ $\mathrm{C}_{14} \mathrm{H}_{14} \mathrm{ClN}_{3} \mathrm{O}_{4} \mathrm{~S}_{2}: 410.0006$. Found: 409.9986.

2-(3-(2-Methoxyphenyl)ureido)-2-oxoethyl(S)-(2-oxotetrahydrofuran-3-yl)carbamodithioate 11b

White solid (TLC: petroleum ether:EtOAc 1:1), (yield $51 \%)$, mp $130-131^{\circ} \mathrm{C} ;{ }^{1} \mathrm{H}-\mathrm{NMR} \quad\left(400 \mathrm{MHz}\right.$, DMSO- $\left.d_{6}\right) \delta$ : 10.99 (s, 1H, -CO-NH-CO-), 10.70 (s, 1H, -CS-NH-), 10.51 (d, $J=8.0 \mathrm{~Hz}, 1 \mathrm{H}, \mathrm{Ar}-\mathrm{NH}-\mathrm{CO}-), 8.16(\mathrm{~d}, J=7.8 \overline{\mathrm{Hz}}, 1 \mathrm{H}, \mathrm{Ar}-\mathrm{H})$, $7.05(\mathrm{~d}, J=3.8 \mathrm{~Hz}, \overline{2 \mathrm{H}}, \mathrm{Ar}-\mathrm{H}), 6.95-6.91(\mathrm{~m}, 1 \mathrm{H}, \mathrm{Ar}-\mathrm{H}), 5.50$ $\left(\mathrm{dt}, J=11.0,8.6 \mathrm{~Hz}, 1 \mathrm{H},-\mathrm{O}-\mathrm{CH}_{2}-\right), 4.41(\mathrm{t}, J=8.4 \mathrm{~Hz}, 1 \mathrm{H}$, -CH-NH-), 4.34-4.27 (m, 3H, -O-CH $\left.-\mathrm{CH}_{2},-\mathrm{CH}_{2}-\mathrm{S}-\right), 3.86$ (s, 3H, Ar-O $\left.-\mathrm{CH}_{3}\right), 2.61-2.57\left(\mathrm{~m}, 1 \mathrm{H},-\overline{\mathrm{O}-\mathrm{CH}_{2}}-\overline{\mathrm{CH}}_{2}-\mathrm{CH}-\right), 2.25-2.20$

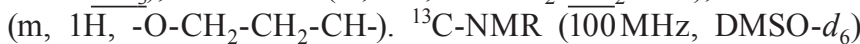
$\delta: 197.3,173.5,169.8,150.2,148.0,126.9,123.5,120.6,119.0$, $110.8,65.5,55.9,54.7,39.0,27.9$. HRESI-MS $\mathrm{m} / \mathrm{z}$ calcd for $[\mathrm{M}+\mathrm{Na}]^{+} \mathrm{C}_{15} \mathrm{H}_{17} \mathrm{~N}_{3} \mathrm{O}_{5} \mathrm{~S}_{2}: 406.0502$. Found: 406.0504 .

2-Oxo-2-(3-(p-tolyl)ureido)ethyl( $S$ )-(2-oxotetrahydrofuran-3yl)carbamodithioate 11c

White solid (TLC: petroleum ether:EtOAc 1:1), (yield 61\%), mp $143-145^{\circ} \mathrm{C}$; ${ }^{1} \mathrm{H}-\mathrm{NMR}\left(400 \mathrm{MHz}\right.$, DMSO- $\left.d_{6}\right) \delta$ : 10.91 (s, $1 \mathrm{H},-\mathrm{CO}-\mathrm{NH}-\mathrm{CO}-), 10.50$ (d, $J=7.9 \mathrm{~Hz}, 1 \mathrm{H},-\mathrm{CS}-\mathrm{NH}-$ ), $10.22(\mathrm{~s}, 1 \mathrm{H}, \overline{\mathrm{Ar}}-\mathrm{NH}-\mathrm{CO}-), 7.40(\mathrm{~d}, J=8.3 \mathrm{~Hz}, 2 \mathrm{H}, \overline{\mathrm{Ar}-\mathrm{H}})$, $7.13(\mathrm{~d}, J=8.3 \mathrm{~Hz}, 2 \mathrm{H}, \mathrm{Ar}-\mathrm{H}), 5.50\left(\mathrm{~m}, 1 \mathrm{H},-\mathrm{O}-\mathrm{CH}_{2}-\right), 4.40$ (t, $J=8.5 \mathrm{~Hz}, 1 \mathrm{H},-\mathrm{CH}-\mathrm{NH}-), 4.33-4.27\left(\mathrm{~m}, 3 \mathrm{H},-\mathrm{O}-\mathrm{CH}_{2}-\right.$, $\left.-\mathrm{CH}_{2}-\mathrm{S}-\right), 2.58\left(\mathrm{~m}, 1 \overline{\mathrm{H},}-\mathrm{O}-\mathrm{CH}_{2}-\mathrm{CH}_{2}-\mathrm{CH}-\right), 2.26-2.19(\mathrm{~m}, 4 \mathrm{H}$,

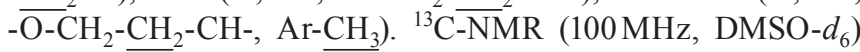
$\delta: 197.3,173.5,170.0,150.4,134.9,132.7,129.3,119.6,65.5$, 54.6, 39.0, 27.9, 20.4. HRESI-MS $\mathrm{m} / \mathrm{z}$ calcd for $[\mathrm{M}+\mathrm{Na}]^{+}$ $\mathrm{C}_{15} \mathrm{H}_{17} \mathrm{~N}_{3} \mathrm{O}_{4} \mathrm{~S}_{2}: 390.0553$. Found: 390.0557 .

2-(3-(4-Methoxyphenyl)ureido)-2-oxoethyl( $S$ )-(2-oxotetrahydrofuran-3-yl)carbamodit-hioate 11d

White solid (TLC: petroleum ether:EtOAc 1:1), (yield $40 \%$ ), mp $100-101^{\circ} \mathrm{C} ;{ }^{1} \mathrm{H}-\mathrm{NMR}\left(400 \mathrm{MHz}\right.$, DMSO- $\left.d_{6}\right) \delta$ : 10.89 (s, $1 \mathrm{H},-\mathrm{CO}-\mathrm{NH}-\mathrm{CO}-), 10.51$ (d, $J=7.3 \mathrm{~Hz}, 1 \mathrm{H},-\mathrm{CS}-\mathrm{NH}-$ ), 10.15 (s, 1H, $\overline{\mathrm{Ar}}-\mathrm{NH}-\mathrm{CO}-), 7.44$ (d, $J=9.0 \mathrm{~Hz}, 2 \mathrm{H}, \overline{\mathrm{Ar}-\mathrm{H}}$ ), $6.91(\mathrm{~d}, J=9.0 \mathrm{~Hz}, 2 \mathrm{H}, \mathrm{Ar}-\mathrm{H}), 5.51(\mathrm{dt}, J=9.8,8.8 \mathrm{~Hz}, 1 \mathrm{H}$, $\left.-\mathrm{O}-\mathrm{CH}_{2}-\right), 4.41(\mathrm{t}, J=8.4 \mathrm{~Hz}, 1 \mathrm{H},-\mathrm{CH}-\mathrm{NH}-), 4.34-4.29$ (m,
$3 \mathrm{H},-\mathrm{O}-\mathrm{CH}_{2}-$, $\left.-\mathrm{CH}_{2}-\mathrm{S}-\right), 3.74$ (s, 3H, Ar-O-CH 3 ), 2.59 (m, $1 \mathrm{H}$, $\left.-\mathrm{O}-\mathrm{CH}_{2}-\mathrm{CH}_{2}-\mathrm{CH}\right), 2.25-2.20$ (m, $1 \mathrm{H},-\mathrm{O}_{-}-\mathrm{CH}_{2}-\mathrm{CH}_{2}-\mathrm{CH}-$ ). ${ }^{13} \mathrm{C}-\mathrm{NMR}\left(100 \mathrm{MHz}, \mathrm{DMSO}-d_{6}\right) \delta: 197.3,173.5,169.9,155.6$, $150.5,130.4,121.4,114.1,65.5,55.2,54.6,39.0,27.9$. HRESIMS $m / z$ calcd for $[\mathrm{M}+\mathrm{Na}]^{+} \mathrm{C}_{15} \mathrm{H}_{17} \mathrm{~N}_{3} \mathrm{O}_{5} \mathrm{~S}_{2}: 406.0507$. Found: 406.0438 .

2-(3-(2-Ethoxyphenyl)ureido)-2-oxoethyl( $S$ )-(2-oxotetrahydrofuran-3-yl)carbamodithi-oate 11e

White solid (TLC: petroleum ether:EtOAc 1:1), (yield $45 \%)$ mp $157-159^{\circ} \mathrm{C} ;{ }^{1} \mathrm{H}-\mathrm{NMR}$ (400 MHz, DMSO- $\left.d_{6}\right) \quad \delta$ : 10.95 (s, 1H, -CO-NH-CO-), 10.73 (s, 1H, -CS-NH-), 10.49 (d, $J=7.9 \mathrm{~Hz}, 1 \mathrm{H}, \overline{\mathrm{Ar}}-\mathrm{NH}-\mathrm{CO}-), 8.16(\mathrm{~d}, J=\overline{8.1} \mathrm{~Hz}, 1 \mathrm{H}$, Ar-H), 7.05-7.00 (m, 2H, Ar-H), 6.94-6.90 (m, 1H, Ar-H), $5.50\left(\mathrm{dt}, J=10.6,8.6 \mathrm{~Hz}, 1 \mathrm{H},-\mathrm{O}-\mathrm{CH}_{2}-\right), 4.40(\mathrm{t}, J=8.4 \mathrm{~Hz}$, $1 \mathrm{H},-\mathrm{CH}-\mathrm{NH}-), 4.33-4.27$ (m, 3H, -O- $\left.\mathrm{CH}_{2}-,-\mathrm{CH}_{2}-\mathrm{S}-\right), 4.10$ (q, $\left.J=7.0 \mathrm{~Hz}, 2 \mathrm{H},-\mathrm{O}-\mathrm{CH}_{2}-\mathrm{CH}_{3}\right), 2.5 \overline{8(\mathrm{~m},} \overline{1 \mathrm{H}},-\mathrm{O}-\mathrm{CH}_{2}-$ $\left.\mathrm{CH}_{2}-\mathrm{CH}-\right), \quad 2.25-2.20\left(\mathrm{~m}, 1 \mathrm{H}, \quad-\mathrm{O}-\mathrm{CH}_{2}-\mathrm{CH}_{2}-\mathrm{CH}-\right), 1.37$ (t, $\left.\bar{J}=6.9 \mathrm{~Hz}, 3 \mathrm{H},-\mathrm{O}-\mathrm{CH}_{2}-\mathrm{CH}_{3}\right) .{ }^{13} \mathrm{C}-\mathrm{NMR}\left(100 \mathrm{MHz}, \mathrm{DMSO}-d_{6}\right)$ $\delta: 197.3,173.5,169.8,150.2,147.2,127.4,123.5,120.6,119.0$, $112.0,65.5,64.2,54.6,39.0,27.9,14.6$. HRESI-MS $\mathrm{m} / \mathrm{z}$ calcd for $[\mathrm{M}+\mathrm{Na}]^{+} \mathrm{C}_{16} \mathrm{H}_{19} \mathrm{~N}_{3} \mathrm{O}_{5} \mathrm{~S}_{2}: 420.0658$. Found: 420.0664 .

2-(3-(Naphthalen-1-yl)ureido)-2-oxoethyl(S)-(2-oxotetrahydrofuran-3-yl)carbamodith-ioate 11f

White solid (TLC: petroleum ether:EtOAc 1:1), (yield $47 \%$ ), mp $151-153^{\circ} \mathrm{C} ;{ }^{1} \mathrm{H}-\mathrm{NMR}$ (400MHz, DMSO- $\left.d_{6}\right) \delta$ : 11.22 (s, 1H, -CO-NH-CO-), 10.99 (s, 1H Ar-NH-CO-), 10.55 (d, $J=7.8 \mathrm{~Hz}, 1 \mathrm{H}, \overline{-\mathrm{CS}}-\mathrm{NH}-), 8.12(\mathrm{~d}, J=7.5 \overline{\mathrm{Hz}}, 1 \mathrm{H}, \mathrm{Ar}-\mathrm{H})$, $7.99(\mathrm{~d}, J=8.1 \mathrm{~Hz}, 1 \mathrm{H}, \overline{\mathrm{Ar}-\mathrm{H}}), 7.93(\mathrm{~d}, J=8.5 \mathrm{~Hz}, 1 \mathrm{H}, \mathrm{Ar}-\mathrm{H})$, $7.75(\mathrm{~d}, J=8.1 \mathrm{~Hz}, 1 \mathrm{H}, \mathrm{Ar}-\mathrm{H}), 7.66(\mathrm{t}, J=7.3 \mathrm{~Hz}, 1 \mathrm{H}, \mathrm{Ar}-\mathrm{H})$, 7.61-7.57 (m, 1H, Ar-H), $7.53(\mathrm{t}, J=7.9 \mathrm{~Hz}, 1 \mathrm{H}, \mathrm{Ar}-\mathrm{H}), 5.53$ (m 1H, -O- $\left.\mathrm{CH}_{2}-\right), 4.44-4.39$ (m, 3H, - $\mathrm{CH}-\mathrm{NH}-,-\mathrm{CH}_{2}-\mathrm{S}-$ ), 4.33-4.29 (m, $\left.1 \mathrm{H},-\mathrm{O}-\mathrm{CH}_{2}-\right), 2.61\left(\mathrm{~m}, 1 \mathrm{H},-\mathrm{O}-\mathrm{CH}_{2}-\mathrm{CH}_{2}-\mathrm{CH}-\right)$,

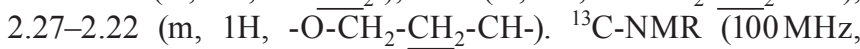
DMSO- $\left.d_{6}\right) \delta: 197.3,173.5, \overline{170.8}, 150.9,133.6,132.4,128.7$, $126.7,126.2,125.8,125.4,124.4,120.2,117.9,65.5,54.7$, 30.7, 27.9. HRESI-MS $m / z$ calcd for $[\mathrm{M}+\mathrm{Na}]^{+} \mathrm{C}_{18} \mathrm{H}_{17} \mathrm{~N}_{3} \mathrm{O}_{4} \mathrm{~S}_{2}$ : 426.0558. Found: 426.0462.

2-(3-(4-Isopropylphenyl)ureido)-2-oxoethyl( $S$ )-(2-oxotetrahydrofuran-3-yl)carbamodi-thioate $\mathbf{1 1 g}$

White solid (TLC: petroleum ether:EtOAc $=1: 1)$, (yield $49 \%$ ), mp $142-144^{\circ} \mathrm{C} ;{ }^{1} \mathrm{H}-\mathrm{NMR}\left(400 \mathrm{MHz}, \mathrm{DMSO}-d_{6}\right) \delta: 10.90$ (s, $1 \mathrm{H},-\mathrm{CO}-\mathrm{NH}-\mathrm{CO}-), 10.50$ (d, $J=7.8 \mathrm{~Hz}, 1 \mathrm{H},-\mathrm{CS}-\mathrm{NH}-$ ), 10.23 (s, 1H, $\overline{\mathrm{Ar}-\mathrm{NH}}-\mathrm{CO}-), 7.43$ (d, $J=8.5 \mathrm{~Hz}, 2 \mathrm{H}, \mathrm{Ar}-\mathrm{H}), 7.20$ $(\mathrm{d}, J=8.5 \mathrm{~Hz}, 2 \overline{\mathrm{H}}, \mathrm{Ar}-\mathrm{H}), 5.52-5.47\left(\mathrm{~m}, 1 \mathrm{H},-\mathrm{O}-\mathrm{CH}_{2}-\right), 4.41$ (t, $J=8.5 \mathrm{~Hz}, 1 \mathrm{H},-\mathrm{CH}-\mathrm{NH}-), 4.34-4.28$ (m, 3H, -O- $\mathrm{CH}_{2}$, $\left.-\mathrm{CH}_{2}-\mathrm{S}-\right), 2.85$ (dd, $\left.\bar{J}=13.8,6.9 \mathrm{~Hz}, 1 \mathrm{H}, \mathrm{Ar}-\mathrm{CH}-\right), 2.61-2.56$ $\left(\overline{\mathrm{m},} 1 \mathrm{H}, \quad-\mathrm{O}-\mathrm{CH}_{2}-\mathrm{CH}_{2}-\mathrm{CH}-\right), 2.25-2.20 \quad\left(\mathrm{~m},-1 \mathrm{H},-\mathrm{O}-\mathrm{CH}_{2}-\right.$ $\left.\mathrm{CH}_{2}-\mathrm{CH}-\right), 1.19$ (d, $\left.J=6.9 \mathrm{~Hz}, 6 \mathrm{H}, \mathrm{Ar}-\mathrm{CH}-\left(\mathrm{CH}_{3}\right)_{2}\right) \cdot{ }^{13} \mathrm{C}-\mathrm{NMR}$ $\left(100 \mathrm{MHz}\right.$, DMSO- $\left.d_{6}\right) \quad \delta: 197.3,173.5,169.9,150.4,143.9$, $135.2,126.7,119.8,65.5,54.6,39.0,32.8,27.9,23.9$. HRESIMS $m / z$ calcd for $\left[\mathrm{M}+\mathrm{H}+\mathrm{CH}_{3} \mathrm{CN}\right]^{+} \mathrm{C}_{17} \mathrm{H}_{21} \mathrm{~N}_{3} \mathrm{O}_{4} \mathrm{~S}_{2}: 437.1312$. Found: 437.1876.

2-Oxo-2-(3-(o-tolyl)ureido)ethyl( $S$ )-(2-oxotetrahydrofuran-3yl)carbamodithioate 11h

White solid (TLC: petroleum ether:EtOAc 1:1), (yield $42 \%$ ), mp $96-97^{\circ} \mathrm{C} ;{ }^{1} \mathrm{H}-\mathrm{NMR}\left(400 \mathrm{MHz}\right.$, DMSO- $\left.d_{6}\right) \delta: 11.04$ (s, $1 \mathrm{H},-\mathrm{CO}-\mathrm{NH}-\mathrm{CO}-), 10.51$ (d, $J=7.9 \mathrm{~Hz}, 1 \mathrm{H},-\mathrm{CS}-\mathrm{NH}-$ ), 10.28 (s, $1 \mathrm{H}, \overline{\mathrm{Ar}-\mathrm{NH}}-\mathrm{CO}-), 7.94$ (d, $J=8.0 \mathrm{~Hz}, 1 \mathrm{H}, \mathrm{Ar}-\mathrm{H}), \overline{7.21}$ (m, $2 \mathrm{H}, \mathrm{Ar}-\mathrm{H}), 7.03$ (t, $J=7.4 \mathrm{~Hz}, 1 \mathrm{H}, \mathrm{Ar}-\mathrm{H}), 5.50(\mathrm{dt}, J=10.8$, $\left.8.6 \mathrm{~Hz}, 1 \mathrm{H},-\mathrm{O}_{-} \mathrm{CH}_{2}-\right), 4.40$ ( $\left.\mathrm{t}, J=8.4 \mathrm{~Hz}, 1 \mathrm{H},-\mathrm{CH}-\mathrm{NH}-\right)$, $4.33-4.27\left(\mathrm{~m}, 3 \overline{\mathrm{H}},-\mathrm{O}-\underline{\mathrm{CH}}_{2}-,-\underline{\mathrm{CH}}_{2}-\mathrm{S}-\right), 2.62-2.55 \overline{(\mathrm{m}}, 1 \mathrm{H}$, 
$\left.-\mathrm{O}-\mathrm{CH}_{2}-\mathrm{CH}_{2}-\mathrm{CH}-\right), 2.28-2.17$ (m, 4H, -O-CH $-\mathrm{CH}_{2}-\mathrm{CH}-, \mathrm{Ar}-$ $\left.\mathrm{CH}_{3}\right) .{ }^{13} \mathrm{C}-\mathrm{NMR}\left(100 \mathrm{MHz}, \mathrm{DMSO}-d_{6}\right) \delta: 197.3,173.5,170.4$, $150.5,135.9,130.3,127.4,126.4,123.9,120.7,65.5,54.7,39.0$ 27.9, 17.5. HRESI-MS $m / z$ calcd for $[\mathrm{M}+\mathrm{Na}]^{+} \mathrm{C}_{15} \mathrm{H}_{17} \mathrm{~N}_{3} \mathrm{O}_{4} \mathrm{~S}_{2}$ : 390.0553. Found: 390.0560 .

2-Oxo-2-(3-(m-tolyl)ureido)ethyl(S)-(2-oxotetrahydrofuran-3-yl)carbamodithioate 11i

White solid (TLC: petroleum ether:EtOAc 1:1), (yield $55 \%$ ), mp $130-131^{\circ} \mathrm{C}$; ${ }^{1} \mathrm{H}-\mathrm{NMR} \quad\left(400 \mathrm{MHz}\right.$, DMSO- $\left.d_{6}\right) \quad \delta$ : 10.93 (s, 1H, -CO-NH-CO-), 10.51 (d, J=7.9 Hz, 1H, -CSNH-), 10.27 (s, 1H, Ar-NH-CO-), 7.36 (s, 1H, Ar-H), 7.32 $\overline{(\mathrm{d},} J=8.2 \mathrm{~Hz}, 1 \mathrm{H}, \mathrm{Ar}-\mathrm{H}) \overline{, 7.21}(\mathrm{t}, J=7.8 \mathrm{~Hz}, 1 \mathrm{H}, \mathrm{Ar}-\mathrm{H}), 6.92$ (d, $J=7.5 \mathrm{~Hz}, 1 \mathrm{H}, \mathrm{Ar}-\mathrm{H}), 5.51$ (dt, $J=11.0,8.6 \mathrm{~Hz}, 1 \mathrm{H},-\mathrm{O}-$ $\left.\mathrm{CH}_{2}-\right), 4.40$ (dd, $\left.J=8.8,7.9 \mathrm{~Hz}, 1 \mathrm{H},-\mathrm{CH}-\mathrm{NH}-\right), 4.33-4.30$ (m, 3H, -O- $\left.\mathrm{CH}_{2}-,-\mathrm{CH}_{2}-\mathrm{S}-\right), 2.59$ (m, 1H, - $\left.-\mathrm{CH}_{2}-\mathrm{CH}_{2}-\mathrm{CH}-\right)$, 2.29-2.23 (m, 4H, -O- $\left.\mathrm{CH}_{2}-\mathrm{CH}_{2}-\mathrm{CH}-, \quad \mathrm{Ar}-\mathrm{CH}_{3}\right) .{ }^{13} \mathrm{C}-\mathrm{NMR}$ $\left(100 \mathrm{MHz}, \mathrm{DMSO}-d_{6}\right) \delta: 197.3,173.5,170 . \overline{0}, 150.4,138.3$, 137.4, 128.8, 124.4, 120.1, 116.7, 65.5, 54.6, 39.0, 27.9, 21.0. HRESI-MS $m / z$ calcd for $[\mathrm{M}+\mathrm{Na}]^{+} \mathrm{C}_{15} \mathrm{H}_{17} \mathrm{~N}_{3} \mathrm{O}_{4} \mathrm{~S}_{2}: 390.0558$. Found: 390.0489 .

General Procedure for the Synthesis of Compounds $12 \mathrm{a}-\mathbf{c}$ In a $25 \mathrm{~mL}$ round bottom flask, the solution of compound $4(150 \mathrm{mg}, 1.09 \mathrm{mmol})$ in acetonitrile was added to corresponding compounds $13 \mathbf{a}-\mathbf{c}(1.20 \mathrm{mmol})$ and $\mathrm{NaHCO}_{3}$ ( $230 \mathrm{mg}, 2.74 \mathrm{mmol})$. After stirring for $8 \mathrm{~h}$ at $75^{\circ} \mathrm{C}$, the solvent was removed under vacuum, extracted with ethyl acetate and water. The organic layer was dried over $\mathrm{MgSO}_{4}$ and evaporated under vacuum to give a residue, which was then subject to column chromatography, affording a white solid $(\mathbf{1 2} \mathbf{a}-\mathbf{c})$.

$(S)-N$ - ((3-Chlorophenyl)carbamoyl)-2-((2-oxotetrahydrofuran-3-yl)amino)acetamide 12a

White solid (TLC: petroleum ether:EtOAc 1:2), (yield $45 \%$ ), mp $133-134^{\circ} \mathrm{C} ;{ }^{1} \mathrm{H}-\mathrm{NMR}\left(400 \mathrm{MHz}, \mathrm{DMSO}-d_{6}\right) \delta: 10.48$ (s, 2H, -CO-NH-CO-, Ar-NH-CO-), 7.78 (d, J=1.9 Hz, 1H, Ar-H), 7.41-7. $\overline{34}$ (m, 2H, A $\overline{r-H}), 7.16$ (d, $J=7.5 \mathrm{~Hz}, 1 \mathrm{H}, \mathrm{Ar}-\mathrm{H})$, $4.33\left(\mathrm{td}, J=8.6,2.2 \mathrm{~Hz}, 1 \mathrm{H},-\mathrm{O}-\mathrm{CH}_{2}-\right), 4.20-4.13(\mathrm{~m}, 1 \mathrm{H},-\mathrm{O}-$ $\left.\mathrm{CH}_{2}-\right), 3.68$ (t, $\left.J=9.2 \mathrm{~Hz}, 1 \mathrm{H},-\overline{\mathrm{CH}}-\mathrm{NH}-\right), 3.55\left(\mathrm{~s}, 2 \mathrm{H},-\mathrm{CH}_{2}-\right.$ $\overline{\mathrm{CO}}-), 2.94$ (s, $1 \mathrm{H},-\mathrm{CH}-\mathrm{NH}-), 2 . \overline{45}$ ( $\left., 1 \mathrm{H},-\mathrm{O}-\mathrm{CH}_{2}-\mathrm{CH}_{2}-\overline{\mathrm{CH}}-\right)$, $2.03-1.98\left(\mathrm{~m}, 1 \mathrm{H},-\mathrm{O}-\overline{\mathrm{CH}}_{2}-\mathrm{CH}_{2}-\mathrm{CH}-\right) .{ }^{13} \mathrm{C}-\mathrm{NMR} \overline{(100 ~ M H z}^{2}$ DMSO- $\left.d_{6}\right) \delta: 177.2,174.2,150.4,139.1,133.2,130.6,123.4$ $119.2,118.2,65.5,55.1,49.8,29.5$. HRESI-MS $\mathrm{m} / \mathrm{z}$ calcd for $[\mathrm{M}+\mathrm{Na}]^{+} \mathrm{C}_{13} \mathrm{H}_{14} \mathrm{ClN}_{3} \mathrm{O}_{4}$ : 334.0571. Found: 334.0530.

$(S)-N$-((2-Methoxyphenyl)carbamoyl)-2-((2-oxotetrahydrofuran-3-yl)amino)acetamide 12b

White solid (TLC: petroleum ether:EtOAc 1:2), (yield $37 \%$ ), mp $121-123^{\circ} \mathrm{C}$; ${ }^{1} \mathrm{H}-\mathrm{NMR} \quad\left(400 \mathrm{MHz}\right.$, DMSO- $\left.d_{6}\right) \quad \delta$ : 10.80 (s, 1H, -CO-NH-CO-), 10.42 (s, 1H, Ar-NH-CO-), 8.16 (d, $J=8.2 \mathrm{~Hz}, 1 \mathrm{H}, \overline{\mathrm{Ar}}-\mathrm{H}), 7.07(\mathrm{~m}, 2 \mathrm{H}, \mathrm{Ar}-\mathrm{H}), \overline{6.9} 6-6.93(\mathrm{~m}$, $1 \mathrm{H}, \mathrm{Ar}-\mathrm{H}), 4.32\left(\mathrm{td}, J=8.6,2.3 \mathrm{~Hz}, 1 \mathrm{H},-\mathrm{O}-\mathrm{CH}_{2}-\right), 4.20-4.15$ $\left(\mathrm{m}, 1 \mathrm{H},-\mathrm{O}-\mathrm{CH}_{2}-\right), 3.88$ (s, 3H, Ar-O-CH $), 3 . \overline{68}(\mathrm{t}, J=9.2 \mathrm{~Hz}$, $1 \mathrm{H},-\mathrm{CH}-\mathrm{NH}-), 3.54\left(\mathrm{~s}, 2 \mathrm{H},-\mathrm{CH}_{2}-\mathrm{CO}-\right), 2.96(\mathrm{~s}, 1 \mathrm{H},-\mathrm{CH}-$ $\mathrm{NH}-), \overline{2.4} 4\left(\mathrm{~m}, 1 \mathrm{H},-\mathrm{O}-\mathrm{CH}_{2}-\mathrm{CH}_{2}-\mathrm{CH}-\right), 2.01$ (m, $1 \mathrm{H},-\mathrm{O}-\mathrm{CH}_{2}-$ $\left.\overline{\mathrm{CH}}_{2}-\mathrm{CH}-\right) .{ }^{13} \mathrm{C}-\mathrm{NMR}\left(100 \mathrm{MHz}, \mathrm{DMSO}-d_{6}\right) \delta: 177.2,174.0$, $\overline{150}^{2} .2,148.0,127.0,123.5,120.6,119.0,110.9,65.5,55.9,55.1$, 49.7, 29.5. HRESI-MS $\mathrm{m} / \mathrm{z}$ calcd for $[\mathrm{M}+\mathrm{Na}]^{+} \mathrm{C}_{14} \mathrm{H}_{17} \mathrm{~N}_{3} \mathrm{O}_{5}$ : 330.1066. Found: 330.1021 .

(S)-N-((4-Methylphenyl)carbamoyl)-2-((2-oxothiotetrahydrofuran-3-yl)amino)acetamide 12c

White solid (TLC: petroleum ether:EtOAc 1:2), (yield $56 \%$ ), mp $119-121^{\circ} \mathrm{C}$; ${ }^{1} \mathrm{H}-\mathrm{NMR} \quad\left(400 \mathrm{MHz}, \mathrm{DMSO}-d_{6}\right) \quad \delta$ : 10.32 (s, 2H, -CO-NH-CO-, Ar-NH-CO-), 7.41 (d, $J=8.4 \mathrm{~Hz}$,
$2 \mathrm{H}, \mathrm{Ar}-\mathrm{H}), 7.15$ (d, $J=8.3 \mathrm{~Hz}, 2 \mathrm{H}, \mathrm{Ar}-\mathrm{H}), 4.33$ (td, $J=8.6$, $\left.2.1 \mathrm{~Hz}, 1 \mathrm{H},-\mathrm{O}-\mathrm{CH}_{2}-\right), 4.19-4.13\left(\mathrm{~m}, 1 \mathrm{H},-\mathrm{O}-\mathrm{CH}_{2}-\right), 3.68(\mathrm{t}$, $J=9.1 \mathrm{~Hz}, 1 \mathrm{H},-\overline{\mathrm{CH}}-\mathrm{NH}-), 3.59-3.49$ (s, 2H, $\left.-\overline{\mathrm{CH}_{2}}-\mathrm{CO}-\right), 2.94$ (s, 1H, -CH-NH-), 2.45 (m, 1H, - $\left.-\mathrm{CH}_{2}-\mathrm{CH}_{2}-\mathrm{CH}-\right), 2.27$ (s, $\left.3 \mathrm{H}, \quad \mathrm{Ar}-\mathrm{CH}_{3}\right), 2.00$ (m, $\left.1 \mathrm{H}, \quad-\mathrm{O}-\mathrm{CH}_{2}-\mathrm{CH}_{2}-\mathrm{CH}-\right) .{ }^{13} \mathrm{C}-\mathrm{NMR}$ $\left(100 \mathrm{MHz}, \mathrm{DMSO}-d_{6}\right) \delta: 177.2,174.2,150.3,135.0,132.7$, 129.3, 119.6, 65.5, 55.1, 49.8, 29.5, 20.3. HRESI-MS $\mathrm{m} / \mathrm{z}$ calcd for $[\mathrm{M}+\mathrm{Na}]^{+} \mathrm{C}_{14} \mathrm{H}_{17} \mathrm{ClN}_{3} \mathrm{O}_{4}: 314.1117$. Found: 314.0547 .

Bacterial Strains and Media Bacterial strains are provided by Ocean University of China. ${ }^{36)}$ Unless otherwise stated, strains were grown in LB medium.

\section{QS Inhibitory Activity Assay}

\section{$P$. aeruginosa PAO1 las System Assay}

Preparation of the QSIS-lasI plate was conducted by the following method. $20 \mathrm{~mL}$ of Luria-Bertani agar (LB agar) $(20 \mathrm{~g} / \mathrm{L})$ was melted and cooled to $50^{\circ} \mathrm{C}$. Gentamicin $(80 \mu \mathrm{g} / \mathrm{mL})$ sucrose $(1 \mathrm{~mL})$, OdDHL $(30 \mathrm{nM})$ and TTC $(2,3$, 5-triphenyltetrazolium chloride) $(250 \mu \mathrm{L})$ were added, the resulting QSIS-lasI solution mixed, and then cultured overnight in LB medium. Agar plates were subsequently prepared by pouring $15 \mathrm{~mL}$ of the mixture into Petri dishes. The medium was allowed to solidify, and then wells were made in the solid gel. All samples including synthesized compounds $(5 \mu \mathrm{L}$, $1.27 \mu \mathrm{g} / \mu \mathrm{L})$, the positive control $\mathrm{C} 30(5 \mu \mathrm{L}, 5 \mathrm{mM})$ and the negative control DMSO $(5 \mu \mathrm{L})$ were added to wells, and the plate was then incubated overnight at $37^{\circ} \mathrm{C}$.

Chromobacterium Violaceum CV026 Inhibition Assay

CV026 was cultured overnight. The cultures $(100 \mu \mathrm{L})$, kanamycin $(15 \mu \mathrm{L}, 20 \mathrm{mg} / \mathrm{mL})$ and C6-HSL $(15 \mu \mathrm{L}, 5 \mathrm{mmol} / \mathrm{L})$ were added to $\mathrm{LB}$ medium $\left(15 \mathrm{~mL}, 40^{\circ} \mathrm{C}\right)$, mixed and poured into Petri dishes. The medium was allowed to solidify, and then the wells were made. All samples including synthesized compounds ( $5 \mu \mathrm{L}, 1.27 \mu \mathrm{g} / \mu \mathrm{L})$, the positive control group (C30; $5 \mu \mathrm{L}, 5 \mathrm{mM}$ ) and the negative control group (DMSO; $5 \mu \mathrm{L}$ ) were added to wells, and the plate was then incubated at $30^{\circ} \mathrm{C}$ for $24 \mathrm{~h}$. The experimental results are shown in Figure S1.

\section{Virulence Factor Assays}

Growth Curve Analysis

$P$. aeruginosa PAO1 was cultured overnight, diluted to OD600 $=0.05$, and then transferred into 96-well plates with active compounds (to give a final concentration of $15 \mu \mathrm{M}$ ). Bacterial cultures were incubated for $24 \mathrm{~h}$ at $37^{\circ} \mathrm{C}$, and optical density was measured at $600 \mathrm{~nm}$ every $2 \mathrm{~h}$.

Detection of Pyocyanin Production

$P$. aeruginosa PAO1 was cultured overnight, diluted with LB medium, and then transferred into 96-well plates with active compounds (to give a final concentration of $15 \mu \mathrm{M}$ ). The bacterial cultures were incubated at $37^{\circ} \mathrm{C}$ for $12 \mathrm{~h}$, and then optical density was measured at $600 \mathrm{~nm}$. $1 \mathrm{~mL}$ of bacterial culture was taken from 96 -well plates and centrifuged at $4^{\circ} \mathrm{C}$ for $10 \mathrm{~min}$. After centrifugation, $1 \mathrm{~mL}$ of chloroform was added to the liquid supernatant and mixed thoroughly. After separation, $250 \mu \mathrm{L}$ hydrochloric acid $(0.2 \mathrm{~mol} / \mathrm{L})$ was added to the chloroform layer. The aqueous phase was separated after 3 min and the $\mathrm{OD}_{520}$ was measured by enzyme-labeled instrument (RT6000 from Rayto, America).

Elastase Activity Assay

PAO1 bacterial cultures $\left(\mathrm{OD}_{600} \approx 1.0\right)$ was diluted, transferred to peptone tryptic soy broth (PTSB) medium. When $\mathrm{OD}_{600} \approx 0.2$, the active compounds into PTSB medium containing PAO1, and then cultured them in the shock conditions. 
Bacterial cultures were centrifuged at $4^{\circ} \mathrm{C}$ for $10 \mathrm{~min}$, and then $500 \mu \mathrm{L}$ of Congo red buffer was added into $500 \mu \mathrm{L}$ of the liquid supernatant. After reacting for $8 \mathrm{~h}$ at $37^{\circ} \mathrm{C}$, the mixture was centrifuged at $4^{\circ} \mathrm{C}$ for $10 \mathrm{~min}$, and sample of the supernatant analyzed by $\mathrm{OD}_{490}$, to reveal the elastase activity.

Determination of Rhamnolipid Production

PAO1 bacterial cultures $(\mathrm{OD} \approx 1.0)$ was diluted, and transferred to $\mathrm{LB}$ medium. When $\mathrm{OD}_{600} \approx 0.2$, the active compounds were added to PTSB medium containing PAO1, then cultured in the shock conditions. The sample was then centrifuged at $4^{\circ} \mathrm{C}$ for $10 \mathrm{~min}$, and a $1 \mathrm{~mL}$ of the liquid supernatant was added to $1 \mathrm{~mL}$ of ether, and shaken for $1 \mathrm{~min}$. A sample of the resulting ether phase $(800 \mu \mathrm{L})$ was transferred to a new tube, then the remaining aqueous solution was extracted once with ether $(1 \mathrm{~mL})$. The ether phases were combined and taken to dryness, and the resulting residue was dissolved in sterile water $(100 \mathrm{~mL})$. The $\mathrm{OD}_{420}$ was measured after the sterile water solution reacted with the orcin sulfuric acid reagent.

Swarming Movement Detection

$P$. aeruginosa PAO1 was cultured overnight, diluted with LB medium, and then centrifuged at $4000 \mathrm{rpm}$ for $4 \mathrm{~min}$. Active compounds were added into the melted swarming medium to give a final concentration of $15 \mu \mathrm{M}$, and the resulting mixture was dried for $3 \mathrm{~min}$, and then incubated with $1 \mu \mathrm{L}$ of concentrated bacterial cultures at $37^{\circ} \mathrm{C}$ for $24 \mathrm{~h}$.

Biofilm Formation Assay

P. aeruginosa PAO1 was cultured overnight, diluted with LB medium, and then transferred into 96-well plates with active compounds $(15 \mu \mathrm{M}$; final concentration). The bacterial cultures were incubated at $37^{\circ} \mathrm{C}$ for $12 \mathrm{~h}$. The cultures were dyed with crystal violet $(0.1 \%)$ for $20 \mathrm{~min}$, and were then washed with normal saline. After drying, acetic acid glacial $(150 \mu \mathrm{L}, 33 \%)$ was added, so that $\mathrm{OD}_{590}$ could be measured.

The mRNA Expression of QS-Related Genes Assay (1) Extraction of total bacterial RNA: P. aeruginosa PAO1 was cultured overnight, then transferred to LB medium and cultured in the shock conditions. When $\mathrm{OD} 600 \approx 0.2$, the test group and control group were respectively added active compounds and blank solvent, then incubated for $6 \mathrm{~h}$. According to the kit instructions, the RNA mass was measured by agarose gel electrophoresis. (2) Reverse transcription to synthesize cDNA: total RNA was used as template, primer $(1 \mu \mathrm{L}, 25 \mu \mathrm{M})$ and of diethyl pyrocarbonate (DEPC) water $(1 \mu \mathrm{L})$ were added, and the mixture was heated at $70^{\circ} \mathrm{C}$ for $10 \mathrm{~min}$ and quenched at $0^{\circ} \mathrm{C}$ for $3 \mathrm{~min} .5 \times$ Moloney Mouse Leukemia Virus (MMLV) buffer $(2 \mu \mathrm{L})$, deoxyribonucleoside triphosphate (DNTP) $(10 \mathrm{mM}, 0.5 \mu \mathrm{L})$, of ribonuclease (RNase) inhibitor RRI $(0.25 \mu \mathrm{L})$, reverse transcriptase MMLV $(0.5 \mu \mathrm{L})$, and DEPC water $(0.75 \mu \mathrm{L})$ were added to the system. The mixture was reacted under the following conditions: $30^{\circ} \mathrm{C}, 10 \mathrm{~min}$; $42^{\circ} \mathrm{C}, 60 \mathrm{~min} ; 70^{\circ} \mathrm{C}, 10 \mathrm{~min}$; after the end of the procedure, the system was placed on ice. (3) Real-time fluorescence quantitative PCR: a cDNA template was diluted 10 times, the reaction system was set according to the kit instructions: the conserved gene 16SrDNA as the internal reference for amplification, $95^{\circ} \mathrm{C}, 10 \mathrm{~min} ; 95^{\circ} \mathrm{C}, 30 \mathrm{~s}, 60^{\circ} \mathrm{C}, 30 \mathrm{~s} ; 4^{\circ} \mathrm{C}, 10 \mathrm{~min}$, but $95^{\circ} \mathrm{C}$, $30 \mathrm{~s}, 60^{\circ} \mathrm{C}, 30 \mathrm{~s} ; 40$ cycles were run. Plot of the dissolution curve: $95^{\circ} \mathrm{C}, 30 \mathrm{~s} ; 60^{\circ} \mathrm{C}, 30 \mathrm{~s} ; 95^{\circ} \mathrm{C}, 30 \mathrm{~s}$. ABI 7500 RT-PCR software was used to analyze the amplification results.

Conflict of Interest The authors declare no conflict of interest.

Supplementary Materials The online version of this article contains supplementary materials.

\section{References}

1) Ren J. L., Zhang X. Y., Yu B., Wang X. X., Shao K. P., Zhu X. G., Liu H. M., Eur. J. Med. Chem., 93, 321-329 (2015).

2) Kasper S. H., Bonocora R. P., Wade J. T., Musah R. A., Cady N. C., ACS Chem. Biol., 11, 1106-1117 (2016).

3) Lee J., Zhang L. H., Protein Cell, 6, 26-41 (2015).

4) Rasmussen T. B., Bjarnsholt T., Skindersoe M. E., Hentzer M. Kristoffersen P., Kote M., Nielsen J., Eberl L., Givskov M., J. Bacteriol., 187, 1799-1814 (2005).

5) Parellada E. A., Ferrero M., Cartagena E., Bardón A., Neske A., Int. Biodeter. Biodegr., 85, 78-84 (2013).

6) Lu Z. H., Wang X. L., Wilson A. D., Dorey-Robinson D. L. W., Archibald A. L., Ait A. T., Frossard J. P., Arch. Virol., 162, 2203-2210 (2017).

7) Williams P., Cámara M., Curr. Opin. Microbiol., 12, 182-191 (2009).

8) Greenberg E. P., Nature (London), 424, 134 (2003).

9) Macedo A. J., Abraham W., Med. Chem., 5, 517-528 (2009).

10) Kordbacheh H., Eftekhar F., Ebrahimi S. N., Microb. Pathog., 110, 390-398 (2017).

11) Kalia V. C., Biotechnol. Adv., 31, 224-245 (2013).

12) El-Mowafy S. A., Shaaban M. I., Abd El Galil K. H., J. Appl. Microbiol., 117, 1388-1399 (2014).

13) Maura D., Hazan R., Kitao T., Ballok A. E., Rahme L. G., Sci. Rep., 6, $34083(2016)$.

14) Pearson J. P., Pesci E. C., Iglewski B. H., J. Bacteriol., 179, 57565767 (1997).

15) Pesci E. C., Milbank J. B., Pearson J. P., McKnight S., Kende A. S. Greenberg E. P., Iglewski B. H., Proc. Natl. Acad. Sci. U.S.A., 96, 11229-11234 (1999).

16) Zhang L. H., Dong Y. H., Mol. Microbiol., 53, 1563-1571 (2004).

17) Defoirdt T., Boon N., Bossier P., PLoS Pathog., 6, e1000989 (2010). 18) Suga H., Smith K. M., Curr. Opin. Chem. Biol., 7, 586-591 (2003).

19) Tiwary B. K., Ghosh R., Moktan S., Ranjan V. K., Dey P., Choudhury D., Dutta S., Deb D., Das A. P., Chakraborty R., Lett. Appl. Microbiol., 65, 2-10 (2017).

20) Arguello J. E., Schmidt L. C., Penenory A. B., Org. Lett., 5, 4133 4136 (2003).

21) Legrand A., Bignon A., Borel M., Zerbib P., Langlois J., Chambon J. P., Lebuffe G., Vallet B., Ann. Fr. Anesth., 24, 807-813 (2005).

22) Chen H. Y., Peng W. T., Lee Y. H., Chang Y. L., Chen Y. J., Lai Y. C., Jheng N. Y., Chen H. Y., Organometallics, 32, 5514-5522 (2013).

23) Zhao W. G., Wang J. G., Li Z. M., Yang Z., Bioorg. Med. Chem. Lett., 16, 6107-6111 (2006).

24) Wellinga K., Mulder R., Van Daalen J. J., J. Agric. Food Chem., 21, 348-354 (1973).

25) Tomlin C. D. S., The Pesticide Manual, 12, 713 (2000)

26) Xu X. J., Wang F., Zeng T., Lin J., Liu J., Chang Y. Q., Sun P. H., Chen W. M., Eur. J. Med. Chem., 144, 164-178 (2018).

27) Wu Y. C., Quan X. C., Si X. R., Int. Biodeter. Biodegr, 99, 39-44 (2015).

28) Ren J. L., Zhang E., Ye X. W., Wang M. M., Yu B., Wang W. H., Guo Y. Z., Liu H. M., Bioorg. Med. Chem. Lett., 23, 4154-4156 (2013).

29) Boyle P. H., Davis A. P., Dempsey K. J., Hosken G. D., Tetrahedron Asymmetry, 6, 2819-2828 (1995).

30) Koch T., Buchardt O., Synthesis-Stuttgart, 1993, 1065-1067 (1993).

31) Kumar B. R. P., Baig N. R., Sudhir S., Kar K., Kiranmai M., Pankaj M., Joghee N. M., Bioorg. Chem., 45, 12-28 (2012).

32) Zhang Z., Wang S., Wan S., Ren S., Li W., Jiang T., Carbohydr. Res., 344, 291-297 (2009). 
33) Yurttas L., Ozkay Y., Akalin-Ciftci G., Ulusoylar-Yildirim S., $J$. Enzyme Inhib. Med. Chem., 29, 175-184 (2014).

34) Shao K., Zhang X., Zhang X., Xue D., Ma L., Zhang Q., Liu H., Chin. J. Chem., 32, 443-447 (2014).

35) Chen K., Hu A., Chen S., Cao G., Wu H., Chin. J. Med. Chem., 13, 286-287 (2003).

36) Zhang M. M., Wang M. J., Zhu X. C., Yu W. G., Gong Q. H., Biotechnol. Lett., 40, 865-870 (2018).
37) Rasmussen T. B., Bjarnsholt T., Skindersoe M. E., Hentzer M. Kristoffersen P., Kote M., Nielsen J., Eberl L., Givskov M., J. Bacteriol., 187, 1799-1814 (2005).

38) Bottomley M. J., Muraglia E., Bazzo R., Carfì A., J. Biol. Chem. 282, 13592-13600 (2007).

39) Yu B., Liu H. Y., Kong X. Y., Chen X. L., Wu C. L., Eur. J. Med. Chem., 163, 500-511 (2019). 